\title{
Stimulus-Dependent Synchronization of Neuronal Responses in the Visual Cortex of the Awake Macaque Monkey
}

\author{
Andreas K. Kreiter and Wolf Singer \\ Max Planck Institute for Brain Research, D-60528 Frankfurt/Main, Germany
}

In visual areas of the cerebral cortex, most neurons exhibit preferences for particular features of visual stimuli, but in general, the tuning is broad. Thus, even simple stimuli evoke responses in numerous neurons with differing but overlapping feature preferences, and it is commonly held that a particular feature is encoded in the pattern of graded responses of the activated population rather than in the optimal responses of individual cells. To decipher this population code, responses evoked by a particular stimulus need to be identified and bound together for further joint processing and must not be confounded with responses to other, nearby stimuli. Such selection of related responses could be achieved by synchronizing the respective discharges at a time scale of milliseconds, as this would selectively and jointly enhance their saliency. This hypothesis predicts that a given set of neurons should exhibit synchronized discharges more often when responding to a single stimulus than when activated by different but simultaneously presented stimuli. To test this prediction, recordings

Most neurons in the visual cortex are coarsely tuned to several different aspects of visual stimuli, such as spatial location, spatial extent, orientation, spectral composition, and the direction of motion (Hubel and Wiesel, 1959, 1962; Zeki, 1975; Orban, 1984; Desimone et al., 1985; Henry, 1985; Maunsell and Newsome, 1987; Livingstone and Hubel, 1988). Therefore, in a particular cell, many different stimuli can elicit responses of similar amplitude. Because of this ambiguity, it is commonly held that even simple features are represented by the pattern of graded responses of a population of neurons and not by individual cells. Because of their combinatorial flexibility, population codes have a high coding capacity and are constitutive in most models exploiting parallel distributed processing (Hebb, 1949; Braitenberg, 1978; Edelman and Mountcastle, 1978; Grossberg, 1980; Abeles, 1982, 1991; Hopfield, 1982; Palm, 1982, 1990; von der Malsburg, 1985; Rumelhart and McClelland, 1986; Singer, 1987, 1990; Zipser and Andersen, 1988; Gerstein et al., 1989; Hopfield and Tank, 1991; Young and Yamane, 1992). However, ambiguities can arise when several stimuli are present simultaneously, in particular when they are spatially contiguous or overlapping. In that case, position coding may not be sufficient to identify responses evoked

\footnotetext{
Received Dec. 4, 1995; accepted Jan. 17, 1996.

We are particularly grateful to Dr. W. T. Newsome for numerous valuable comments on this manuscript. We thank Johanna Klon-Lipok for excellent technical assistance, Renate Ruhl-Völsing for preparing the graphics, and Drs. P. König and T. Schillen for the permission to use several of their data analysis programs.

Correspondence should be addressed to Dr. Andreas K. Kreitcr, Max Planck Institute for Brain Research, Deutschordenstrasse 46, D-60528 Frankfurt/Main 71, Germany.

Copyright $(C) 1996$ Society for Neuroscience $0270-6474 / 96 / 162381-16 \$ 05.00 / 0$
}

were performed with two electrodes from spatially segregated cells in the middle temporal area (MT) of the awake behaving macaque monkey. It was found that cells with overlapping receptive fields, but different preferences for directions of motion, can engage in synchronous activity if they are stimulated with a single moving bar. In contrast, if the same cells are activated with two different bars, each moving in the direction preferred by the cells at the two respective sites, responses show no or much fewer synchronous epochs. Control experiments exclude that this effect is attributable to changes in response amplitude, the mere presence of two stimuli, or the specific orientation of the bars. The critical variable determining the strength of correlation is the extent to which both sites are activated by a common stimulus or by two different stimuli with different directions of motion.

Key words: synchronization; extrastriate cortex; V5; area $M T$; binding problem; temporal coding; neural assembly; cross-correlation

by a particular stimulus and to distinguish these from responses to other, nearby stimuli. Theoretical considerations (Milner, 1974; Grossberg, 1980; von der Malsburg, 1985, 1986; von der Malsburg and Schneider, 1986; von der Malsburg and Singer, 1988; Gerstein et al., 1989; Abeles, 1991) and experimental evidence from the visual cortex of cats and monkeys (for review, see Singer, 1993) suggest that temporal synchronization of action potentials within the millisecond range could serve to prevent false conjunctions in the processing of population responses. Synchronization enhances selectively and jointly the saliency of all responses that contain episodes of synchronous spiking because synchronous EPSPS summate optimally in target cell populations. If temporal synchronization is exploited by the nervous system to select constellations of responses for further joint processing, then the responses evoked by the same stimulus are expected to contain such synchronous cpisodes much more frequently than responses evoked by different stimuli.

To test this prediction, we investigated response synchronization in the middle temporal area (area V5 or MT) of alert fixating macaque monkeys. This area is involved in visual motion processing as indicated by the response properties of the neurons (Dubner and Zeki, 1971; Zeki, 1974a,b; Van Essen et al., 1981; Maunsell and Van Essen, 1983a,b; Movshon et al., 1985; Mikami et al., 1986a,b; Newsome et al., 1986, 1989; Lagae et al., 1989, 1993; Rodman and Albright, 1989; Snowden et al., 1991; Born and Tootell, 1992; Britten et al., 1992; Mikami, 1992; Olavarria et al., 1992; Stoner and Albright, 1992) and the results of lesion (Newsome et al., 1985; Newsome and Paré, 1988; Cowey and Marcar, 1992; Marcar and Cowey, 1992) and stimulation experiments 
(Salzman et al., 1990, 1992; Murasugi et al., 1993). We have chosen this area because the neuron's broad tuning for the direction of motion suggests that the motion trajectories of stimuli are encoded by population responses (Churchland and Sejnowski, 1992; Rolls, 1992; Young and Yamane, 1992; Gochin et al., 1994). To examine our hypothesis, we recorded simultaneously with two electrodes neuronal responses from different sites. The stimuli were configurated so that cells at the two recording sites were either activated by a common stimulus (single-bar condition) or by two different bars, whereby each bar activated predominantly the cells at only one recording site (dual-bar condition). These responses were then subjected to cross-correlation analysis to examine whether synchronization is indeed stronger among different cells if these cells are activated by the same stimulus and weaker if they respond to different stimuli.

Preliminary accounts of the results have been published in abstract form (Kreiter and Singer, 1993, 1994).

\section{MATERIALS AND METHODS}

Behavioral procedure. Two male macaque monkeys (1 Macaca mulatta and 1 Macaca fascicularis) were trained to maintain fixation of a light spot (Wurtz, 1969). For this purpose, each monkey sat in a primate chair with the eyes $57 \mathrm{~cm}$ in front of a CRT screen. The behavioral task started with the appearance of a $0.25^{\circ}$ diameter light spot. Within $3 \mathrm{sec}$ the monkey had to start fixation and subsequently press a lever. Fixation had to be maintained for a randomly chosen interval of 4-6 sec after pressing the lever. Then the light spot dimmed slightly and the monkey was required to release the lever within 400-500 msec. After a successful trial, a drop of juice was delivered and a waiting period of $2-3 \mathrm{sec}$ started. If the monkey made a saccade that deviated its gaze by $>0.7^{\circ}$ from the fixation point as measured by an infrared occulometer while the lever was pressed, or if it released the lever before the dimming period, the trial was automatically stopped, the fixation point disappeared, and the waiting period started without reward. If the monkey discontinued work it was brought back into the home cage. Water and fruit were supplemented as necessary. After implantation of the head holder, the head was restrained and eye movements were monitored with an infrared eye-tracking system.

Surgery. After completion of the initial training, the monkeys were prepared for head fixation and chronic recording by implantation of a head holder and a recording cylinder with $20 \mathrm{~mm}$ diameter. After termination of recording from the first cylinder of one of the monkeys, a second cylinder was implanted over the other hemisphere. For surgery, anesthesia was induced with an injection of ketamine $(10 \mathrm{mg} / \mathrm{kg}$, i.m.), and after tracheal intubation, continued with 1-3\% isofluorane in oxygen/ nitrous oxide $(30 / 70)$. The recording cylinders were oriented approximately perpendicular to the surface of the brain in a region close to the foveal representation in V1/V2 and the adjoining prelunate gyrus. Headholder, cylinders, and screws were fixed and interconnected with dental acrylic. Postoperative treatment included local and systemic application of antibiotics for $5 \mathrm{~d}$. All surgical procedures were performed in accordance with the guidelines for the welfare of experimental animals issued by the federal government of Germany.

Recording technique. Multi- and single-unit recordings were obtained from area MT with two to four varnish-coated tungsten microelcetrodes. Their tapered tips were exposed over a length of $8-20 \mu \mathrm{m}$ and coated with platinum black. This resulted in an impedance of $0.5-3 \mathrm{M} \Omega$ at $1 \mathrm{kHz}$. The individually movable electrodes were advanced with hydraulic microdrives arranged in a rhomboid array with interelectrode distances of $-0.5 \mathrm{~mm}$. The electrodes were introduced approximately perpendicular to the surface of the brain in a region of the prelunate gyrus close to the foveal representation in V1/V2. In several cases, the electrodes were introduced via a 23 gauge guide tube with its tip located 3-6 mm above the target area. The signal of each electrode was amplified $(10,000 \times)$, band pass-filtered from $1-3 \mathrm{kHz}$, and fed to a Schmitt trigger with the threshold set to at least 2 times the amplitude of the noise. The resulting pulse sequences were digitized at a rate of $1 \mathrm{kHz}$ and stored on disk of a computer. The start of each recorded sweep was synchronized with the vertical retrace signal of the CRT used for visual stimulation. Trials in which the monkey made an error were automatically discarded. On several occasions, more selective electrodes were used to record not more than one to three cells simultaneously. The waveform of each spike was digitized with a rate of $31.25 \mathrm{kHz}$. Waveforms evoked by individual units were identified by their similar form and amplitude with standard spike separation techniques (Schmidt, 1984a,b).

Area MT was identified by its position in the superior temporal sulcus (STS), the characteristic direction selectivity of its neurons, the size/ eccentricity ratio of the receptive fields (RFs), the typical sequence of RF locations along the electrode tracks, and its position relative to adjoining areas. The extent of the RFs, approximated by rectangles, and their preferred direction of motion were determined by hand mapping with light bars.

Generation of stimuli. Light stimuli consisting of moving bright bars and the fixation spot were generated on a CRT display located $57 \mathrm{~cm}$ in front of the monkeys eyes. The CRT had a resolution of $1024 \times 768$ pixels, subtended a visual angle of $35 \times 26.25^{\circ}$, and operated with a frame rate of $80 \mathrm{~Hz}$ (noninterlaced), which is well above the temporal resolution of monkey retinal ganglion cells (Boynton and Baron, 1975). Control measurements with stimuli provided by an optical bench system and a direct current-driven light source have shown that the $80 \mathrm{~Hz}$ frame rate does not influence the temporal structure of the spikc trains (Kreiter and Singer, 1992). The dimensions of the light bars varied from $0.3 \times 2.5^{\circ}$ to $1 \times 12^{\circ}$, and their velocity from 2 to $6.7^{\circ} / \mathrm{sec}$. Direction of stimulus motion was always orthogonal to the long axis of the light bar. The luminance of the background and of the stimuli was $<0.1 \mathrm{~cd} / \mathrm{m}^{2}$ and $2-12 \mathrm{~cd} / \mathrm{m}^{2}$, respectively.

Stimulus configurations and experimental procedure. After reaching area MT, recording sites were searched and had to have the following properties. First, responses had to be stable and strong to provide enough entries for cross-correlation analysis. Second, at least at two sites neurons had to have partially or fully overlapping RFs and moderately different preferred directions of motion to allow for the required tests. After such a constellation was found, the outlines of the RFs (defined as the minimal response fields) were plotted, and the dircetional tuning of the responses were estimated as the range of directions in which the hand-controlled bars elicited a discernible response as determined from listening to the audio monitor. Subsequently, two different stimulus configurations were arranged. First, neurons at both sites were activated simultaneously with a single-bar stimulus that moved in a direction intermediate between the preferred directions of motion of the two sites (single-bar condition). The size and velocity of the stimulus were adjusted to optimize responses at both sites. Subsequently, the neurons at the two sites were activated with two moving bars, whereby directions of motion were selected so that each bar activated the neurons at one site optimally and influenced those at the other as little as possible (dual-bar condition). Thus, in this configuration two bars moved in different directions, crossed one another during their motion, and each activated neurons mainly at one of the two sites. The stimuli were adjusted to cross the RFs of cells at the two sites at the same time to elicit simultaneous responses. In most cases, size, velocity, and luminance of the stimuli were the same in the single- and dual-bar condition. If, after sampling of a few sweeps, no correlation was observed for any condition, or if it was not possible to arrange one of the stimulus configurations, the search for further sites was immediately resumed and no further attempt was made to document any properties of the present recording sites to save the restricted recording time. We are thus unable to quantify the incidence of correlated firing among MT cells in general. If a correlation was observed, the recordings were stabilized by gently retracting the electrodes to counteract dimpling effects, which are considerable when multielectrode arrays arc uscd. Subsequently, responses to 10 or more computer-controlled presentations were recorded for each of the two stimulus configurations within one measurement, and at least two measurements were obtained in alternation for both conditions. 'To document the effect of each individual bar in the dual-bar condition, we recorded in several cases $(n=16)$ the responses to only one bar with the respective other switched off.

In a further paradigm, the single bar of the first condition was presented together with a second orthogonally oriented bar that moved in an approximately perpendicular direction across the first bar. The precise direction of motion of this second bar was adjusted to minimize its effect on both sites and in most cases was offset by $90^{\circ}$ from that of the first bar (crossing-bar condition). In this configuration, responses from both sites are evoked essentially by only one of the two bars, whereas in the dual-bar condition, responses from the two sites are evoked by different bars. In all but two cases measurements with the crossing-bar condition were preceded and followed by recordings with the single-bar condition. In about half of the cases (5/11), this sequence was repeated 2 or 3 times.

Data analysis. The data recorded from multi- and single-unit record- 
ings are expected to differ systematically with respect to several properties as, for example, the mean firing rate or the absolute size of correlations. For this reason, both types of recordings were analyzed separately and are presented in succession. To compare the degree of synchronization among the responses from the two recording sites for different stimulus conditions quantitatively, we computed crosscorrelograms with $1 \mathrm{msec}$ resolution and $\pm 63 \mathrm{msec}$ maximal shift. These were then summed over all trials of a measurement and, in the case of single-unit recordings, over all trials of all measurements with identical stimulus conditions to achieve a sufficient amount of entries. The correlograms were computed from response segments within windows that included the overlapping part of the major responses from both recording sites. To determine size and position of this window, peristimulus time histograms (PSTHs) and cross-PSTHs were computed with a bin width of $20 \mathrm{msec}$. They were averaged over all measurements recorded for the same stimulus condition and smoothed with a 21 bin box car algorithm to achieve the smooth time course necessary for the determination of the window borders. The average spontaneous rates estimated from the first second of the sweeps were subtracted. Start and end of the windows were set to include the range around the peak of the cross-PSTH where it reached at least $50 \%$ of its maximum and where the individual responses exceeded $30 \%$ of their respective maxima. This procedure ensured that in the dual-bar condition, weak responses preceding and following the main response were excluded because these might have contained discharges evoked by the nonoptimal bar if it entered or left the RFs before or after the other, preferred bar crossed over the RFs. In that case, the responses at both sites would have been evoked by the same bar and, during these short-response epochs, the stimulus constellation would have resembled the single-bar condition.

To check for any signs of stimulus-induced correlations, the averagc over the shift predictors of all possible orders was computed for each measurement in exactly the same window in which the crosscorrelogram was estimated (Perkel et al., 1967b). This predictor contains less noise than the original cross-correlogram (Fig. 1) and is thus a particular sensitive tool to identify even very small stimulus-induced peaks that would hardly be visible in the more noisy cross-correlogram. Because the formal quantitative analysis described below, as well as visual inspection, showed that the predictors contained no peaks, a subtraction of the shift predictor was not necessary. This avoids several problems that occur if the precision of quantitative estimates from individual correlograms are important: (1) Subtraction of a noisy signal from another one increases the absolute amount of noise. This compromises the detection and quantification especially of small peaks. (2) Dependent on the amount of rate covariations (Zohary et al., 1994), predictors can become smaller than the actual offset of the correlogram and thus a part of the correlograms' offset remains also after subtraction of the predictor. A peak will therefore easily become overestimated if its amplitude is directly read from the difference correlogram. The offset, on the other hand, is underestimated. Because estimation of correlation strength depends on the ratio of peak height over offset height, it is considerably more precise to estimate both properties within the same step from the raw correlogram if this is justified by flat predictors. (For a detailed description of various aspects of crosscorrelation as a method to analyze neuronal spike trains and discussions of its features, see Perkel et al., 1967a,b; Moore et al., 1970; Gerstein and Pcrkel, 1972; Bryant et al., 1973; Perkel, 1975; Brillinger et al., 1976; Kirkwood, 1979; Abeles, 1982; Aertsen and Gerstein, 1985; Gerstein and Aertsen, 1985; Gerstein et al., 1985; Aertsen et al., 1986, 1989, 1994; Palm et al., 1988; Boven and Aertsen, 1990; Eggermont, 1990, 1991; Acrtsen and Prei $\beta 1,1991$; König, 1994.)

For peak identification and quantitative description, the resulting raw cross-corrclograms and predictor corrclograms were fitted (LcvenbergMarquardt algorithm) (Press et al., 1986) with the sum of a generalized gabor function and a gaussian of the form:

$$
\begin{aligned}
y=A_{1} \times \exp \left(-\left((t-P) / D_{1}\right)^{E}\right) \times \cos ((t-P) \times F)+C+ \\
A_{2} \times \exp \left(-\left((t-P) / D_{2}\right)^{2}\right) .
\end{aligned}
$$

$P$ is the temporal shift of the function versus the origin, $F$ is the frequency, and $C$ is the constant offset. The decay constant $D_{1}$ and the exponent $E$ determine the form of the pcak. $A_{1}$ and $A_{2}$ are the amplitudes of the gaborian and gaussian part of the function. $D_{2}$ is the decay constant of the gaussian (for a detailed description of the fitting methods, see König, 1994). Because the gaussian contributed either primarily to the peak with
$D$, being only a few milliseconds, or primarily to the offset with $D_{2}$ being much larger, two cases were distinguished for the definition of peak amplitude $(A)$ and offset $(O)$ of the cross-corrclogram:

$$
\begin{aligned}
& A=A_{1}+A_{2} \quad \text { and } \quad O=C \quad \text { if } \quad D_{2} \leq 1 / F \\
& A=A_{1} \quad \text { and } O=A_{2}+C \quad \text { if } \quad D_{2} \gg 1 / F
\end{aligned}
$$

Both values were normalized to one sweep and a window width of $1 \mathrm{sec}$ to facilitate quantitative comparisons of $A$ and $O$ between different cases.

To describe the magnitude of the correlation independently of the firing rate and the length of the analyzed data segment, we computed the normalized correlation $(N C)$ as the amplitude of the peak of the fitted function (height above offset) divided by the amplitude of the offset and multiplied this ratio with 100 to express it in percent:

$$
N C=A / O \times 100 .
$$

$N C$ was set to zero if the peak amplitude of the fitted function was not significantly different from the offset ( $5 \%$ criterion), as it is for flat correlograms. In addition, we computed the average firing rate within the window used for the computation of the cross-corrclogram. For the comparison of different stimulus conditions, the values computed for files obtained with the same stimulus condition were averaged. In general, mean values will be given in the text followed by the standard deviation and the median value in brackets

\section{RESULTS}

\section{The recording sites}

In a typical track through the posterior bank of the caudal STS, the first cells encountered were often difficult to drive, not directional-selective, sometimes tuned for wavelength, and not necessarily orientation-selective. After a sequence of such neurons, a sharp transition occurred in cells that were usually easy to drive and almost always direction-selective. All recordings were taken from this latter region. As the electrode was advanced farther down in the depth of the STS, RF positions shifted from the lower to the upper visual field. Tracks that straddled the STS somewhat deeper and within this direction-selective zone reached a farther border beyond which RFs became much larger, the functional organization more heterogeneous, and neurons often difficult to drive with bar stimuli. Considering the penetration angle, which is not in the standard stereotaxic plane (see Materials and Methods), this sequence of different response properties is characteristic for traversing visual areas V4/V4t, MT, and MST/ FST, which are found in that order if one moves from the posterior top edge of the caudal STS downward into its caudal bank (Gattass and Gross, 1981; Van Essen et al., 1981; Desimone and Ungerleider, 1986).

Quantitative data for the evaluation of the effect of different stimulus configurations were recorded from 26 pairs of multi-unit recording sites in three hemispheres of two monkeys. At all 52 sites the neurons were direction-selective. Their average tuning width was $110 \pm 32^{\circ}\left(104^{\circ}\right)$. The RFs of the investigated sites were in most cases confined to the hemifield contralateral to the recorded hemisphere and had diameters ranging from 2 to $24^{\circ}$ (mean value: $7.4 \pm 4.5^{\circ}$, median: $6.4^{\circ}$ ). The eccentricity of the RF centers ranged from 3.3 to $15.3^{\circ}$ and was on average $6.9 \pm 2.7^{\circ}$ $\left(6.2^{\circ}\right)$. Together with the sequential change of RF properlies characteristic of the different visual areas encountered along the tracks and the position of the electrodes relative to the foveal representation of V1 (see Materials and Methods), these RF properties indicate that all recording sites were in the motionsensitive area MT.

The RFs of all pairs of recording sites overlapped at least partially. The distance between the RF centers was on average $2.7 \pm 1.4^{\circ}\left(2.7^{\circ}\right)$ and ranged from 0.6 to $6.8^{\circ}$. The difference in 

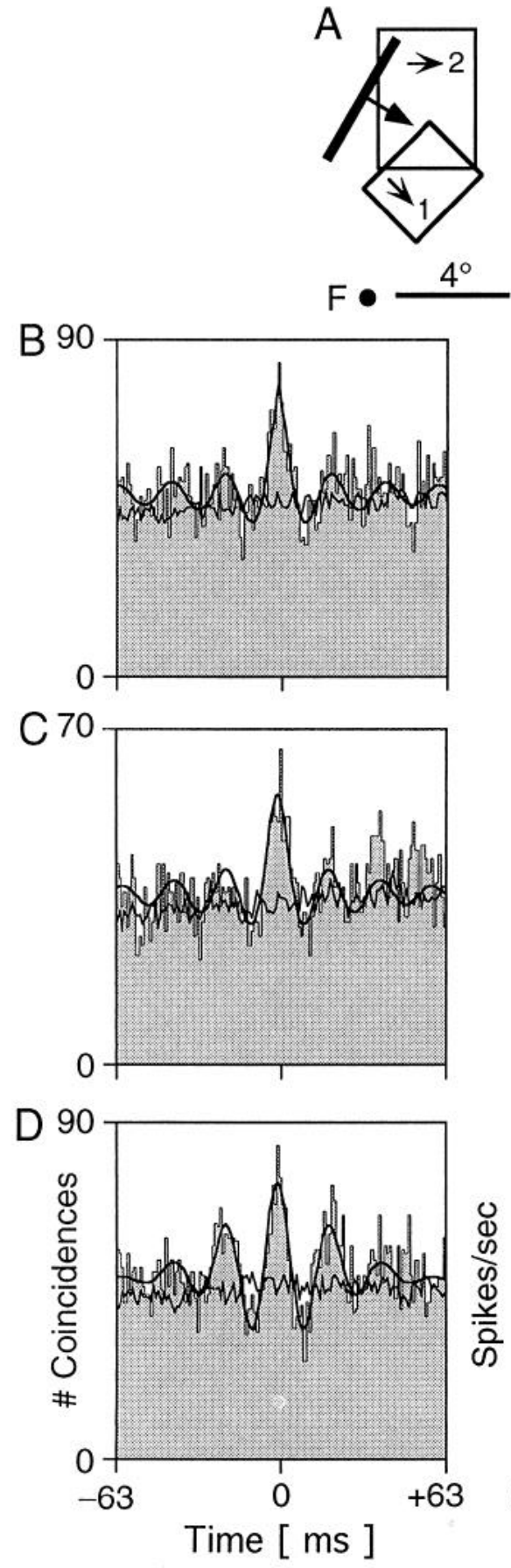
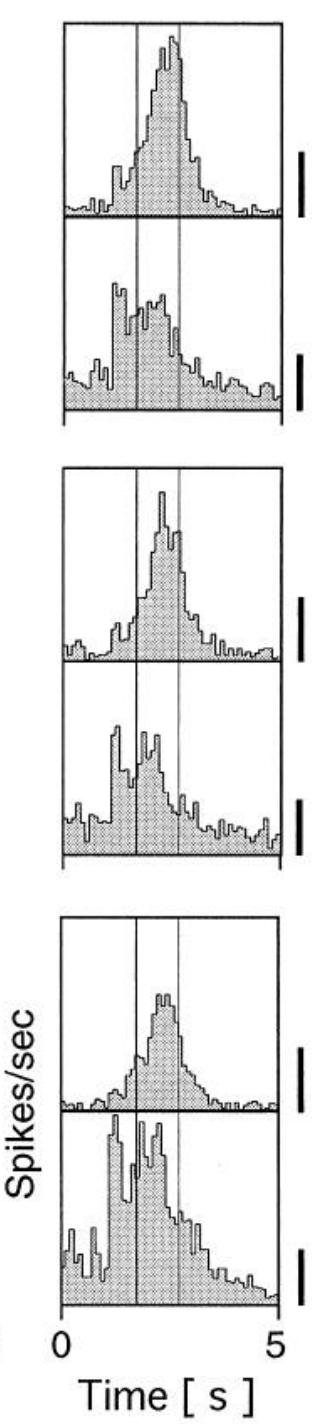
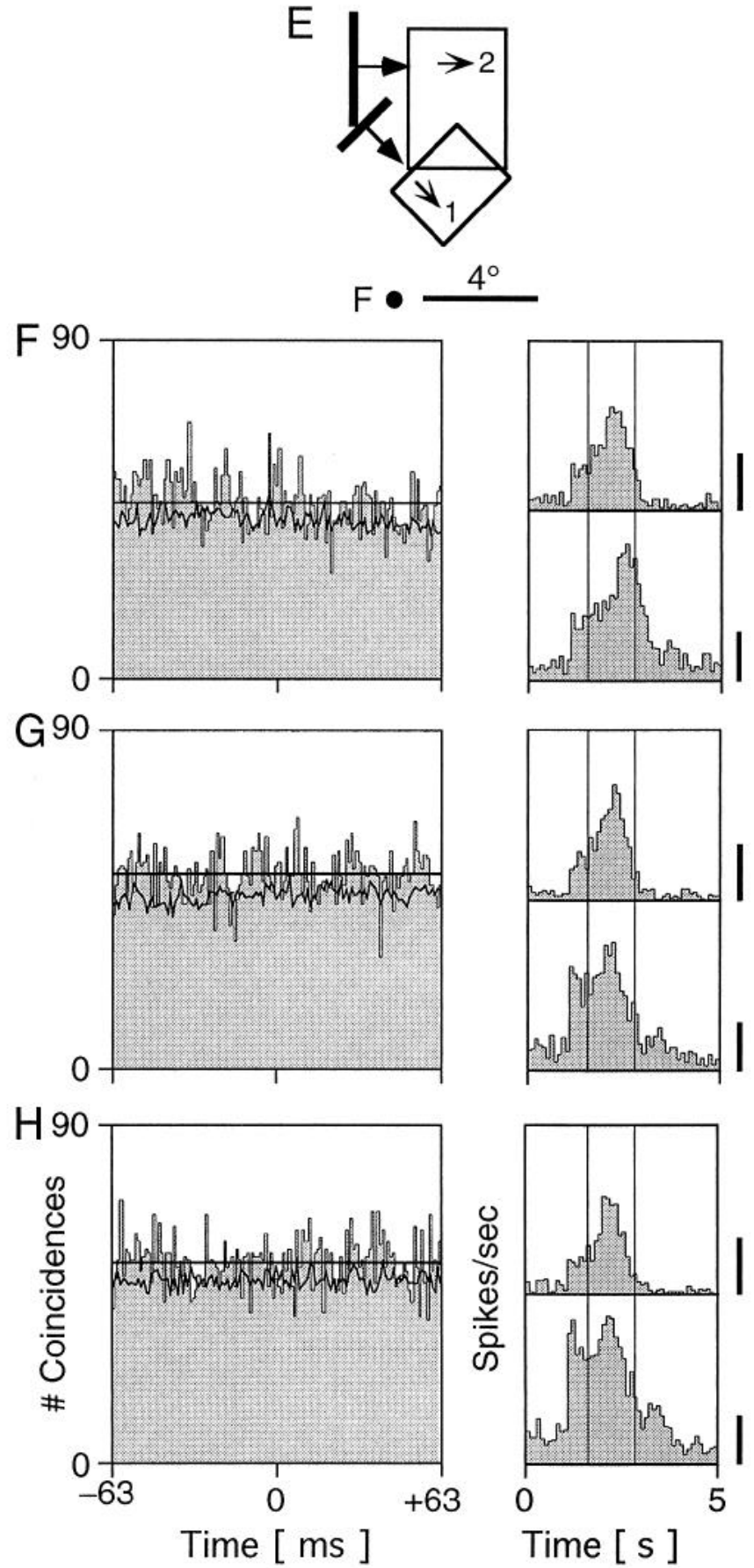

Figure 1. Dependence of synchronization on single- and dual-bar configuration. $A, E$, Plots of the RFs and stimulus configurations. The dot marked $F$ corresponds to the fixation point. Arrows within the RF plots indicate the preferred direction of motion for the neurons at the respective recording sites, and arrows at stimulus bars indicate the direction of motion. $A$ depicts the single and $E$ the dual-bar configuration. The two conditions were alternated in six blocks of 10 trials. Cross-correlograms and PSTHs obtained for the single-bar condition are shown in $B-D$ and those for the dual-bar condition in $F-H$. Upper and lower PSTHs of each figure correspond to RF 1 and 2, respectively. Stimuli began to move 1 sec after trial start and continued moving for $3 \mathrm{sec}$. The thin vertical lines in the PSTHs mark the window over which the cross-correlograms were computed. The scale bars for the PSTHs correspond to $40 \mathrm{spikes} / \mathrm{sec}$. The thick black lines in the cross-correlograms correspond to the fitted functions used for quantification of correlation strength, and the thin black lines correspond to the shift predictor. Note the pronounced synchronization in the single-bar condition and the absence of synchronization in the dual-bar condition.

preferred direction of motion within pairs was between 15 and $120^{\circ}$ with a mean value of $58.8 \pm 28.4^{\circ}\left(60^{\circ}\right)$.

\section{Stimulus dependence of synchronization}

In all 26 pairs of recording sites, synchronization was strongly dependent on the stimulus configuration. A typical example of the observed interactions is shown in Figure 1 . If the cells at both recording sites were activated with a single bar moving into a direction between the respective preferred directions of motion (single-bar condition, Fig. $1 A$ ), the cross-correlograms had a pronounced center peak with an average $\mathrm{NC}$ of $53.9 \%$ (Fig. $1 B-D$ ). 


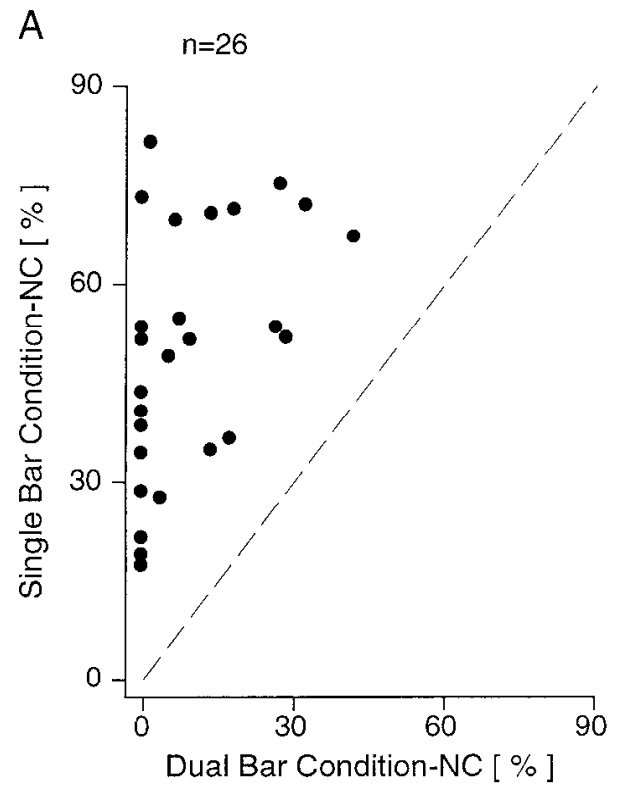

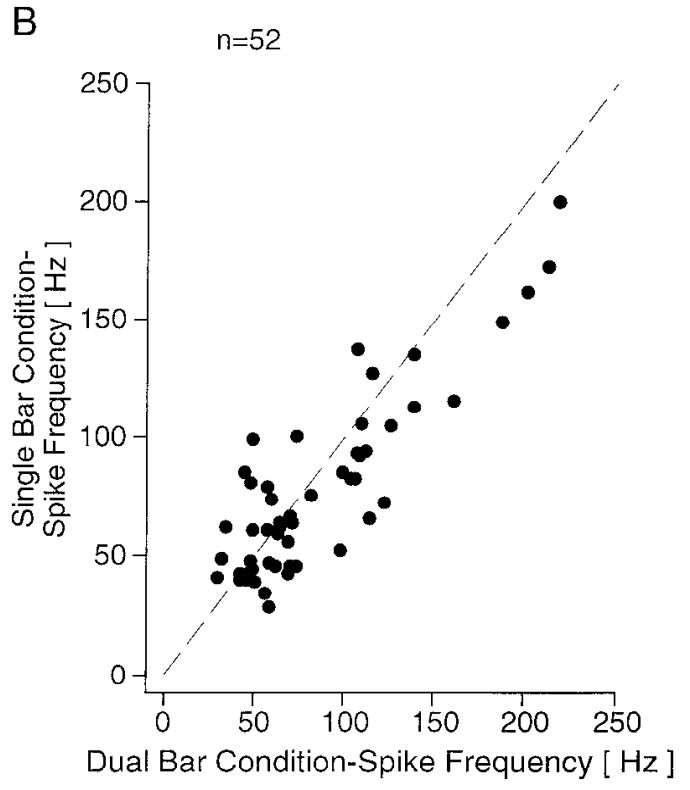

Figure 2. A, Scatter plot of $\mathrm{NC}$ values $(n=26)$ obtained for the single-bar condition (ordinate) against those obtained for the dual-bar configuration (abscissa). The dashed line indicates the region of equal values for both conditions. In all cases, synchronization is considerably stronger for the single-bar condition. $B$, Scatter plot of firing rates at the same recording sites as in $A$ obtained for the single- (ordinate) and dual-bar (abscissa) configuration. Most values are scattered around the dashed line, indicating equal response strength for both conditions. On average, there is a weak reduction of firing rate for the single- compared with the dual-bar condition.
This indicates that the two spike trains contained synchronized discharges, which were not caused by stimulus coordination as indicated by the flat shift predictors. When both sites were stimulated simultaneously with two independent bars, each one moving in a direction that activates essentially only one of the sites (dual-bar condition, Fig. 1E), the cross-correlograms were flat, implying that no synchronization had occurred between the spike trains of both recording sites (average $\mathrm{NC}=0 \%$, Fig. $1 F-H$ ). Alternating presentation of the two different stimulus conditions confirmcd that these results arc robust and repcatablc. Unlike the degree of synchronization, the level of activation of the neurons at both sites was similar for both stimulus conditions. Two further examples with stronger overlap of RFs are shown in Figure $7 A, B$ and Figure $8 A, B$.

The quantitative relation between the normalized correlation for single- and dual-bar conditions in all experiments $(n=26)$ is slown in a scatter plot (Fig. $2 A$ ). Without exception, the dual-bar condition resulted in a much weaker correlation than the singlebar condition or in no correlation at all. Comparison of NC values obtained from the same sites with the dual- and the single-bar condition revealed that the former reached, on average, only $17.3 \%(10.7 \%)$ of the latter, which is a reduction by a factor of $\sim 6$. The mean NC values over all cases were $49.6 \%$ (51.6\%) for the single-bar condition and $10.4 \%(5.2 \%)$ for the dual-bar condition. Within the data segments used for the correlation analysis, the average firing rates were similar for the two stimulus conditions (Fig. $2 B$ ). For individual recording sites, the firing rates for the single-bar condition were, on average, $96.8 \%(89.9 \%)$ of those for the dual-bar condition. When averaged over all sites, the mean firing rates were $79.5 \mathrm{~Hz}(68.2 \mathrm{~Hz})$ for the single- and $87.8 \mathrm{~Hz}$ $(71.3 \mathrm{~Hz})$ for the dual-bar condition. This difference is attributable to the fact that in the dual-bar condition, the activating bars match the preferred direction of motion of the two cell groups more closely than the intermediately oriented bar in the single-bar condition. The reduction of spike frequency in the single-bar condition resulted in an average decrease of the offset of the cross-correlograms by $7.6 \%(20.7 \%)$, or a factor of $1.08(1.26)$, compared with the dual-bar condition. 'I his difference in firing frequency and correlation offset cannot account for the factor 6 difference between the respective NC values. This agrees with the finding that the absolute amplitude of the correlation peak measured from offset was in all cases smaller for the dual- than for the single-bar condition. In the dual-bar condition, the absolute pcak amplitude $(A)$ of the correlation peak was, on average, only $36.9 \%$ of that in the single-bar condition, although in the latter, spike rates were reduced. Therefore, the differences of the NC values do result mostly from changes in the absolute amount of correlation.

The positions of the correlation peak in the cross-correlogram represent the temporal shift between the correlated spike pairs. Usually these peaks were centered close to $\pm 0 \mathrm{msec}$ and there were no significant differences in this respect between the two stimulus conditions. The mean absolute deviation of the peak from the origin of the cross-correlogram was $1.38 \pm 1.1 \mathrm{msec}$ (1.31 $\mathrm{msec})$ for the single-bar condition and $2.0 \pm 0.3 \mathrm{msec}(2.0 \mathrm{msec})$ for the residual peaks in the dual-bar condition. Thus, the peaks that usually extend 3-6 msec to each side of their center always straddled the origin, and the deviation from precise synchrony is small compared with peak width.

In the single-bar condition, $\mathrm{NC}$ values could be quite different for different pairs of recording sites. We suspected that correlation strength might depend on the angular difference between the preferred directions of motion of cells at the two recording sites (Fig. $3 A, B$ ). The Pearson correlation coefficients for the relation between the difference of the preferred directions of motion and the strength of correlation in the single- and the dual-bar condition were not significant $(r=-0.257, p>0.05$ and $r=-0.311$, $p>0.05$, respectively), but Spearman's rank correlation coefficient revealed a weak dependence for both conditions $\left(\mathrm{r}_{\mathrm{S}}=\right.$ $-0.453, p<0.05$ and $\mathrm{r}_{\mathrm{S}}=-0.38, p<0.05$, respectively). However, the large scatter and the relatively shallow regression lines shown in Figure 3 do not suggest a particularly strong effect of the difference between the preferred directions of motion on the strength of correlation in the present sample.

A stronger dependence was found between the strength of the residual correlations observed in the dual-bar condition and the extent to which each of the two bars coactivated neurons at the respective nonoptimal site. The extent of coactivation was measured for 16 pairs by presenting each of the bars of the dual-bar stimulus in isolation and detcrmining response amplitudes in the same temporal 
A

Figure 3. Dependence of $\mathrm{NC}$ values (ordinate) on the difference between preferred directions at the two recording sites for the single- $(A)$ and the dual-bar $(B)$ condition. For both conditions, a weakly significant relation was found between both variables.

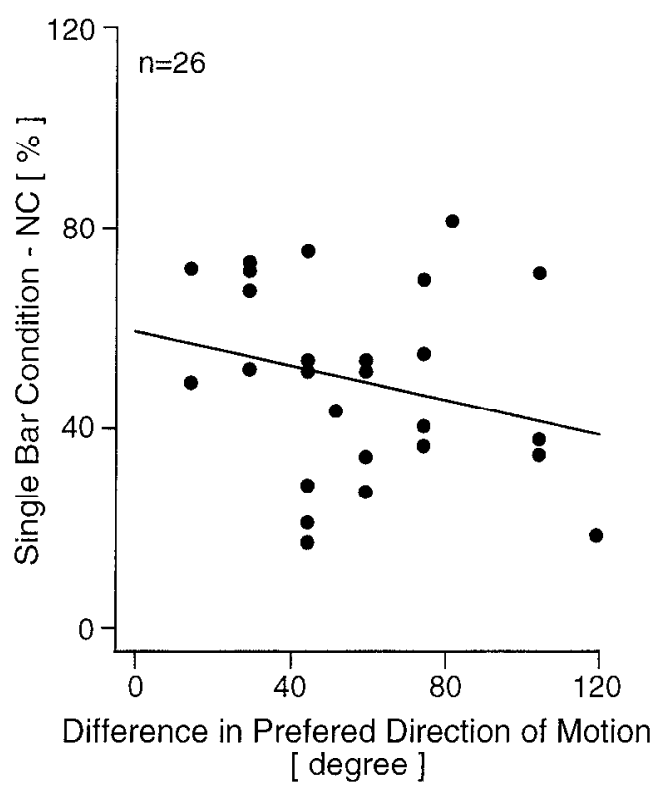

B

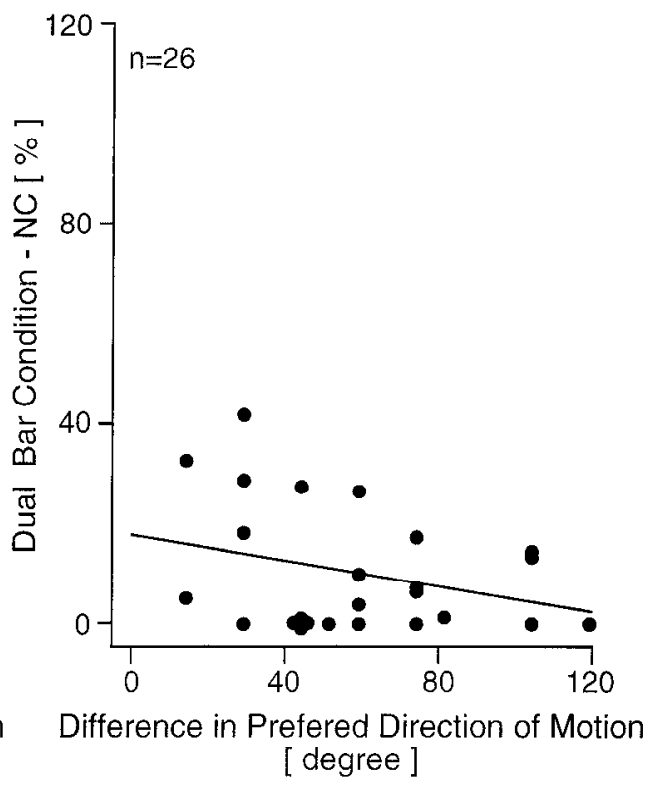

windows that had been used for the analysis of the dual-bar stimulus. Coactivation was expressed as the activity evoked at the same site by the nonoptimal single stimulus divided by the response evoked by the dual-bar stimulus. The coactivation values from both sites were averaged. The residual correlation observed in the dual-bar condition was expressed as a fraction of the correlation strength measured in the single-bar condition.

Comparison of these values revealed that the residual correlations in the dual-bar condition are positively corrclated with the extent of coactivation. As shown in Figure 4, there is a strong dependence between coactivation and correlation strength, which is highly significant $(r=0.632, p<0.005)$. Thus, the more the cells at both sites are driven by the same bar in the dual-bar configuration, the stronger the observed correlation or, in other terms, the more exclusively each bar activates only the site with matching preference, the smaller the correlation.

\section{The influence of a crossing bar}

To test whether the strong reduction of synchronization in the dual-bar condition is attributable solely to the simultaneous presence of more than one moving bar, we tested a modified dual-bar condition for 11 pairs of recording sites in the following way. One bar was configurated as in the single-bar condition, i.e., its direction of motion was intermediate between the preferred directions of the two sites, and the second bar was moved in a direction orthogonal to that of the first (crossing-bar condition, Fig. 5D). Thus, in the case of the crossing-bar condition, two bars were moving simultaneously over the RFs as in the dual-bar condition, but activation of the neurons of both sites is attributable to only one of them, as it is in the single-bar condition. An example of such an experiment is illustrated in Figure 5. Stimulation with the single-har stimulus results in clear synchronization with an average $\mathrm{NC}$ of $44.5 \%$ (Fig. $5 B, C$ ). The simultaneous presentation of the second bar (Fig. 5E), which had only a small influence on the neurons at both recording sites, does not disrupt synchronization (Fig. $5 E, F)$. The average $\mathrm{NC}(53.5 \%)$ is even somewhat enhanced. In contrast, for the conventional dual-bar condition the $\mathrm{NC}$ had been reduced to $7.4 \%$ (data not shown).
Comparison of $\mathrm{NC}$ values and firing rates for all 11 cases in which single- and crossing-bar conditions have been tested shows that there are no significant differences between the variables in the two stimulus conditions (Fig. 6).

The average firing rates for the single- and the crossing-bar condition were $94.6 \mathrm{~Hz}(77.8 \mathrm{~Hz})$ and $106.6 \mathrm{~Hz}(97.7)$, and the mean NC values $47.6 \%(55.3 \%)$ and $45.3 \%(48.7 \%)$, respectively. The NC values in the crossing-bar condition reached, on average,

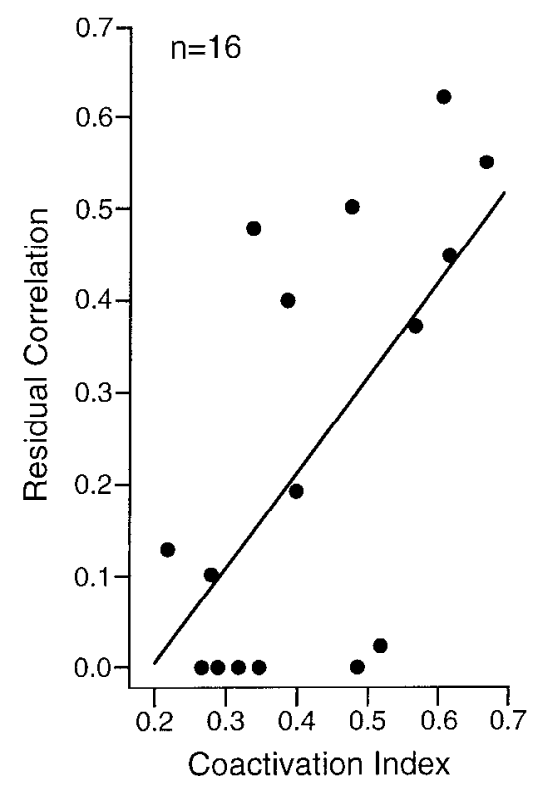

Figure 4. Relation between the residual correlation found in part of the cases for the dual-bar condition and the extent of coactivation of the two sites by the respective nondominant bar. Coactivation is expressed as the average of the two ratios between the respective nondominant responses and the responses evoked at corresponding sites by the dual-bar stimulus. Residual correlation is expressed as the ratio of the $\mathrm{NC}$ values measured in the dual-bar condition over those measured in the single-bar condition. Note that the residual correlation increases with increasing coactivation of both sites by the same bar $(r=0.632, p<0.005)$. 


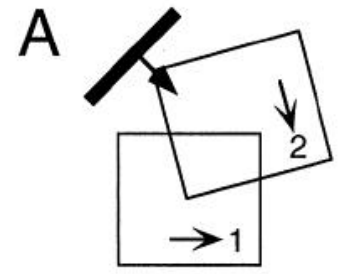

F

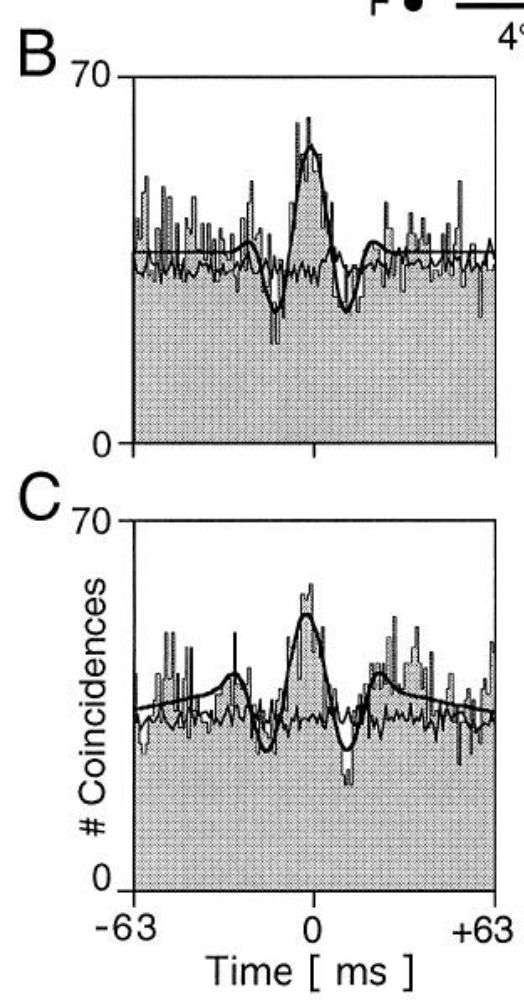

$4^{\circ}$
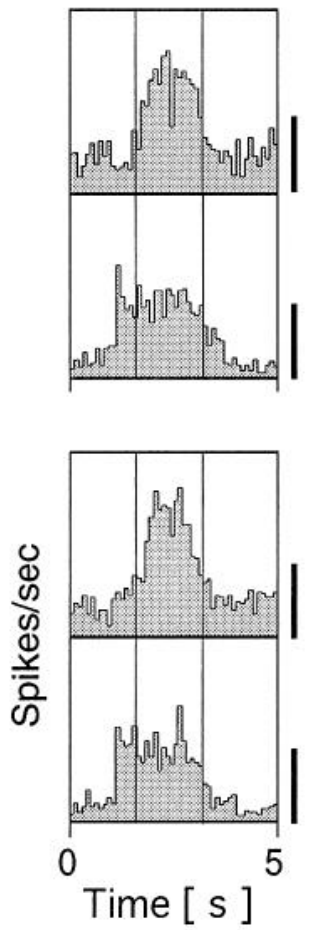

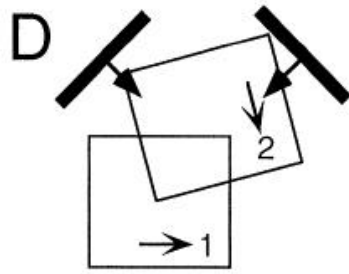

F
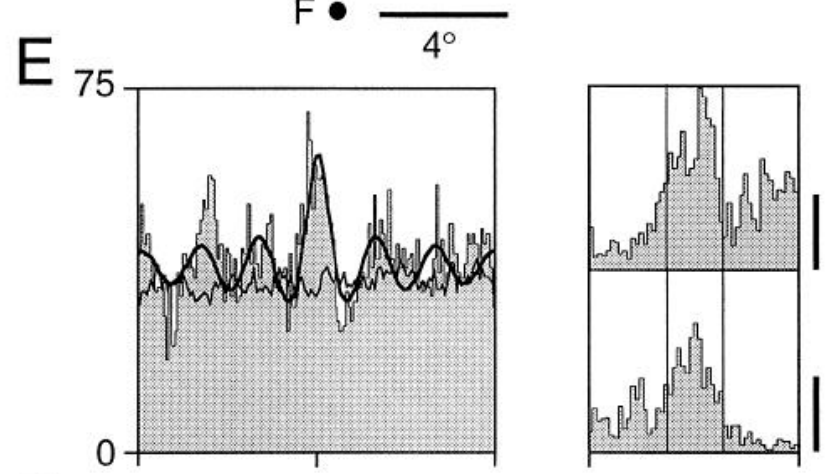

F
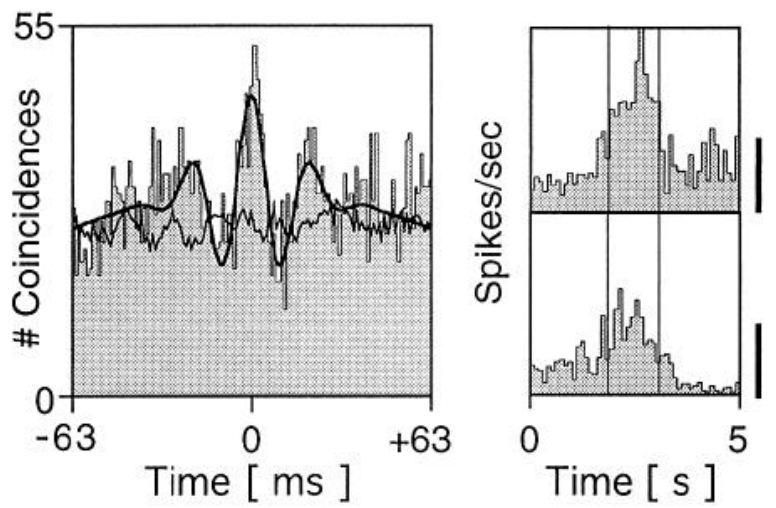

Figure 5. Comparison of synchronization in the single- and crossing-bar configuration: $A, D$, Plots of RFs and stimulus configurations. $A$ depicts the single-bar condition and $D$ the crossing-bar condition. The two stimulus conditions were applied in alternating blocks of 10 trials. Cross-correlograms and PSTHs obtained for the single-bar condition are shown in $B$ and $C$ and those for the crossing-bar condition in $E$ and $F$. The scale bars for the PSTHs correspond to 40 spikes/sec. Other conventions as in Figure 1. Note that the additional bar in the crossing-bar configuration causes no major reduction of synchronization compared with the reduction found for the dual-bar configuration. In this case, the average $\mathrm{NC}$ was $44.5 \%$ for the single-bar configuration, $53.5 \%$ for the crossing-bar configuration, and $7.4 \%$ for the dual-bar configuration (data not shown).

$97.4 \%(104.1 \%)$ of those obtained in the single-bar condition at the same pair of recording sites. Thus, the mere presence of a second bar cannot be the cause for the decrease of synchronization in the dual-bar condition.

\section{The influence of stimulus direction}

The conditions that led to strong synchronization (single- and crossing-bar conditions) had in common that one bar was moving in an intermediate direction between the preferred directions of motion of both sites. To test whether the lack of synchronization in the dual-bar condition is attributable to the absence of a bar with these specifications, we analyzed correlations among responses to single bars, the orientation and direction of motion of which differed from that used in the standard single-bar condition.

Figure 7 shows an example in which first the single-bar stimulus (Fig. 7A) and then the dual-bar stimulus (Fig. $7 B$ ) was presented to establish the stimulus dependence of synchronization as described above. The respective NC values of the two samples were 60.4 and $8.5 \%$. Subsequently, another single bar was presented with an orientation and direction of motion $15^{\circ}$ different from that of the previously applied single-bar stimulus (Fig. $7 C$ ). This resulted in a clear synchronization $(\mathrm{NC}=60.4 \%)$ similar to the one observed with the first single-bar stimulation. In another measurement, the orientation and the direction of motion of the single-bar stimulus were made even more different from the initial single-bar condition and were actually identical to the parameters of one of the two bars used in the dual-bar condition (Fig. 7D). Nevertheless, the responses from the two sites remained strongly correlated with an NC value of $65.8 \%$. A further control measurement with the single-bar condition revealed an NC value of $54.5 \%$ (Fig. $7 E$ ).

Figure 8 shows a case in which both of the bars of the dual-bar condition were able to drive both sites if presented individually. In the standard single-bar condition, the NC value was $65.0 \%$ and dropped to $36.8 \%$ in the dual-bar condition as in the previous examples (Fig. $8 A, B$ ). However, if only one of the bars of the dual-bar configuration is presented (Fig. $8 C, D$ ), then responses are even somewhat stronger correlated as in the standard single- 
A

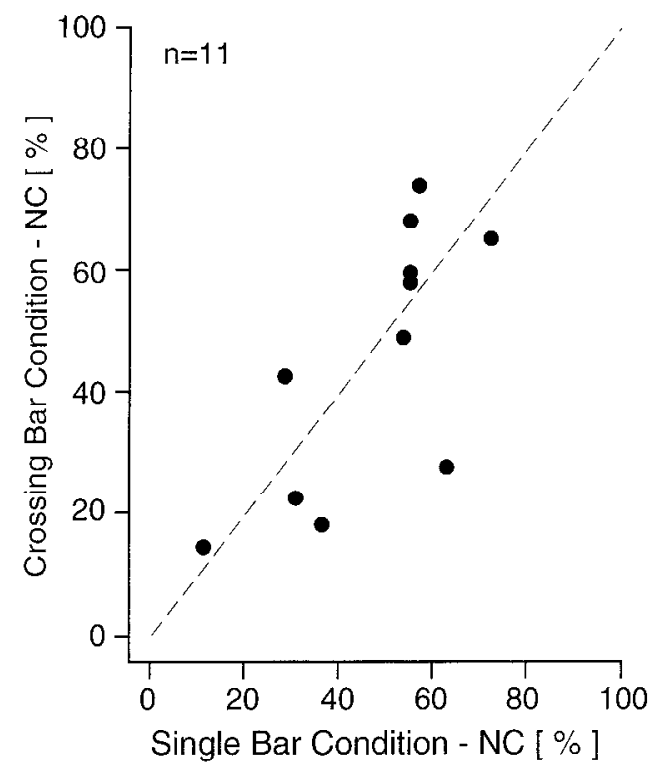

B

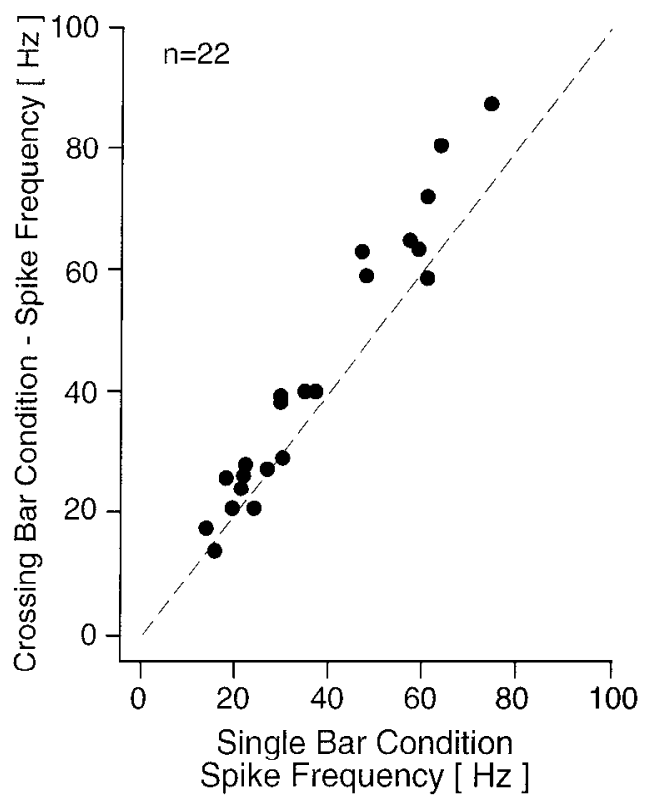

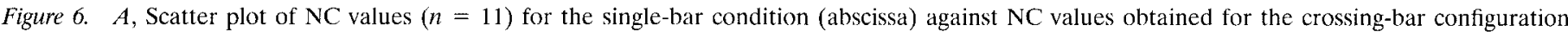

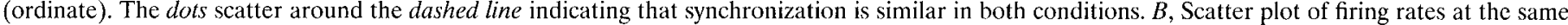

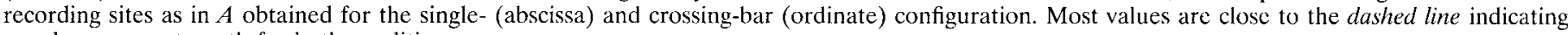
equal response strength for both conditions.

bar condition with NC values of 74.5 and $69.3 \%$, respectively. The subsequent control measurement with the single-bar condition gave an $\mathrm{NC}$ value of $68,6 \%$, proving the stationarity of conditions (Fig. 8E).

These control experiments indicate that the orientation and direction of motion of an individual bar is not critical for the synchronization of the spike trains at both sites, as long as both sites are sufficiently stimulated by the same bar. Furthermore, the breakdown of synchronization in the dual-bar condition cannot be attributed to the particular orientation and direction of motion of any of the two bars, because each of them when presented alone can induce synchronization.

To quantify this result, we selected those cases in which at least one of the two bars used in the dual-bar condition elicited a response at both sites that was strong enough to compute a reliable cross-correlogram (rate increase of response $>20 \mathrm{~Hz}$ compared with spontaneous activity and $>15$ counts per bin in the cross-correlogram; $n=17$, taken from 12 different pairs of recording sites). When this single bar was used for stimulation, it caused an asymmetric activation of the two sites, with an average response rate within the response segment used for the computation of the cross-correlograms of $118.7 \pm 60.6 \mathrm{~Hz}(94.5 \mathrm{~Hz})$ for the matching and $66.0 \pm 24.6 \mathrm{~Hz}(60.0 \mathrm{~Hz})$ for the nonmatching sites. In most cases (Fig. 9), this single-bar stimulus induced correlations that were of similar magnitude as those obtained with the standard single-bar condition. Ilowever, in some cases synchronization was much weaker or absent. On average, the NC values were $84.5 \%(86.0 \%)$ of those obtained with standard single-bar condition, which corresponds to a factor of $1.18(1.16)$. This reduction is small compared with the factor 3.4 reduction observed for the dual-bar condition in the same set of recording pairs. This confirms that the strong reduction of synchronization in the dual-bar condition cannot be attributed to the absence of a stimulus with properties of the bar used in the single-bar condi- tion, because even the bars of the dual-bar condition can induce synchronization when presented individually.

\section{Stimulus-dependent synchronization between individual neurons}

To control for the possibility that changes in correlation strength result from changes in the composition of the set of activated neurons rather than from actual changes in correlation among given pairs of neurons, six pairs of single units were tested with the single- and the dual-bar configuration. In all cases, the correlation observed in the single-bar condition was strongly reduced or disappeared for responses to the dual-bar stimulus. An example is shown in Figure 10. When the two cells were activated with a single bar moving in a direction between the respective preferred directions of motion, the cross-correlogram had a pronounced center peak with an NC of $41.7 \%$ (Fig. 10A). For the dual-bar condition, the NC of the same two cells was reduced to $12.8 \%$ (Fig. 10B). This is close to the value predicted by the relation between the coactivation values and residual correlations shown in Figure 4. The coactivation value in this case is 0.588 , predicting a residual correlation of 0.408 , which corresponds to an $\mathrm{NC}$ of $17.0 \%$

Comparison of $\mathrm{NC}$ values obtained from the same pairs with the dual- and the single-bar condition revealed that the former reached, on average, only $10.2 \%(0.0 \%)$ of the latter. The mean $\mathrm{NC}$ values over all cases were $56.6 \%(60.6 \%)$ for the single-bar condition and $4.4 \%(0.0 \%)$ for the dual-bar condition. This change of correlation was not associated with systematic changes of the spike rates. Averaged over all sites, the firing rates within the data segments used for the correlation analysis were $24.3 \mathrm{~Hz}$ $(20.1 \mathrm{~Hz})$ in the single-bar condition and $25.3 \mathrm{~Hz}(18.4 \mathrm{~Hz})$ in the dual-bar condition. Thus, correlations between single cells show a similar dependence on stimulus configurations as those between multi-unit activity. 

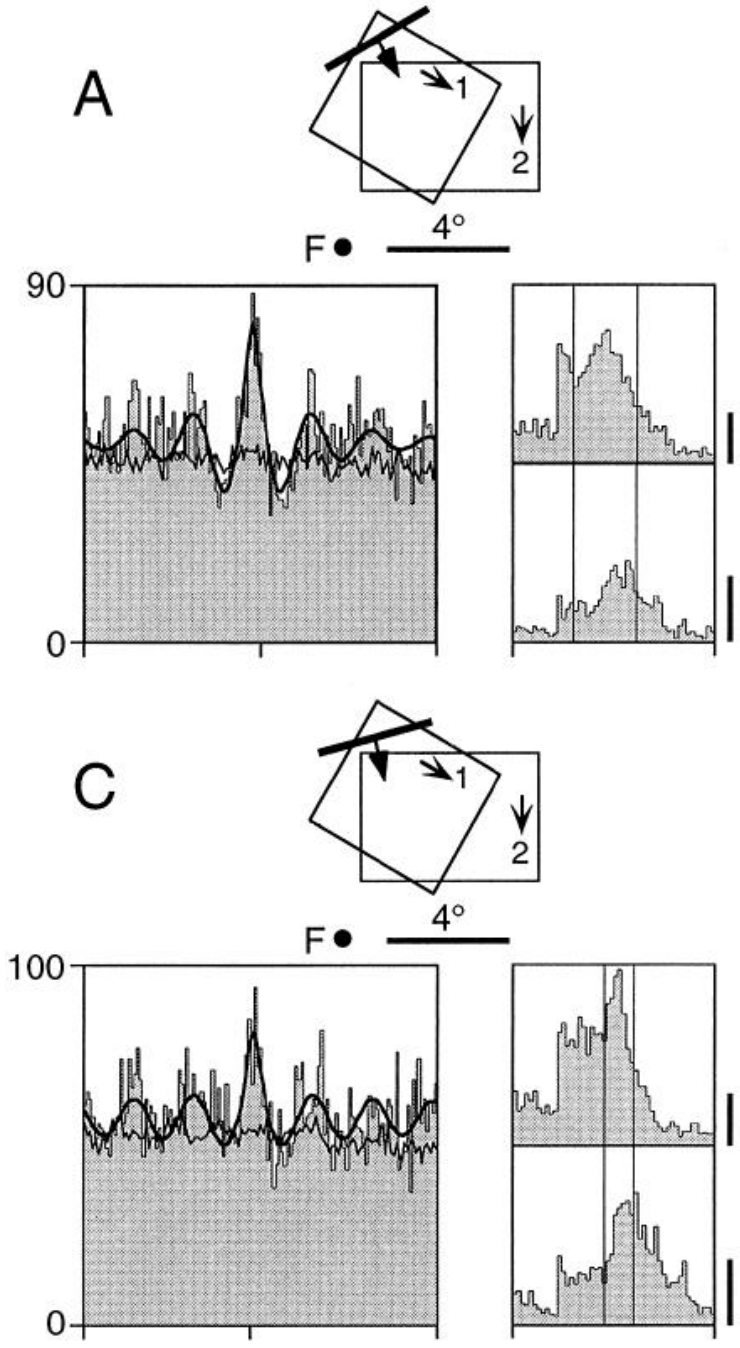

B

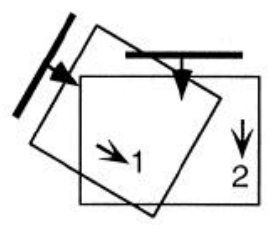

F
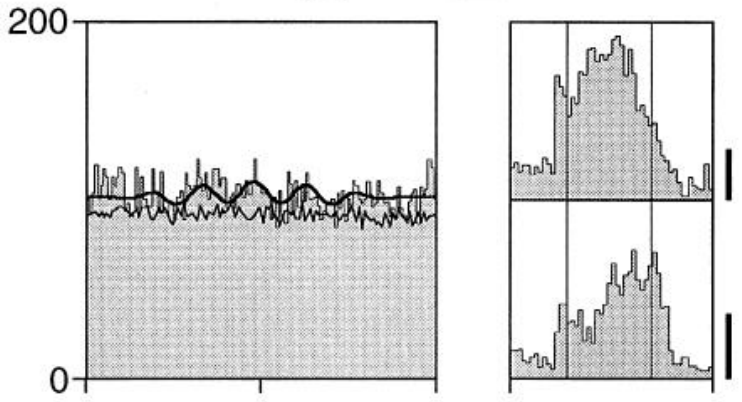

$\mathrm{D}$

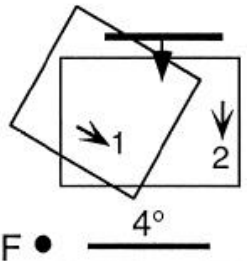

$\mathrm{F}$
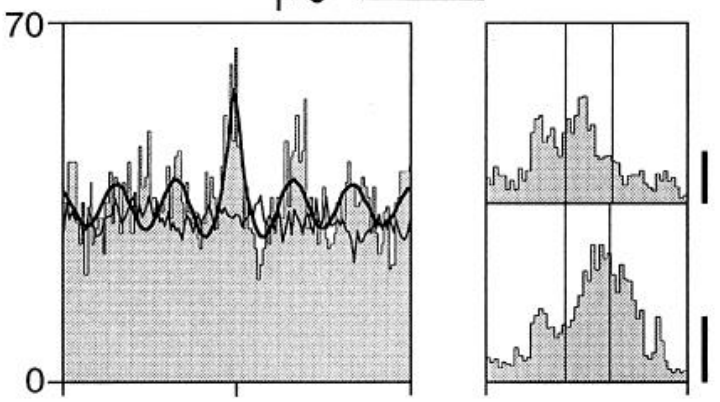
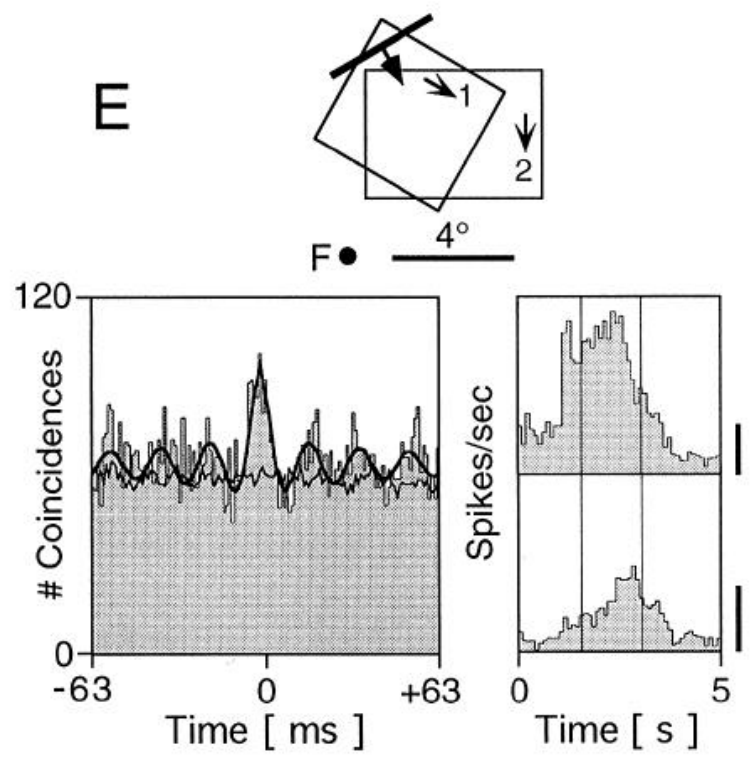

Figure 7. Dependence of synchronization on different directions of motion. Conventions for data presentation are the same as in Figure 1. RF location and stimulus configurations are indicated in the plots above the respective cross-correlograms and PSTHs. The single-bar configuration ( $A$, repetition in $E$ ) resulted in a strong correlation $(\mathrm{NC}=60.4 \%$ in $A$ and $54.5 \%$ in $E$ ) that almost disappeared in the dual-bar configuration $(B$; $\mathrm{NC}=8.5 \%)$. Changing orientation and direction of motion of the single bar by $15^{\circ}$ resulted only in a limited change of correlation $(C ; \mathrm{NC}=40.6 \%)$. In $D$, the orientation and direction of motion of the single bar is changed further so that it equals the right bar of the dual-bar configuration shown in $B$ and stimulates site 1 only poorly. Note that the $\mathrm{NC}$ value is even slightly higher than in the original single-bar condition $(\mathrm{NC}=65.8 \%)$. The scale bars for the PSTHs correspond to 40 spikes/sec. 


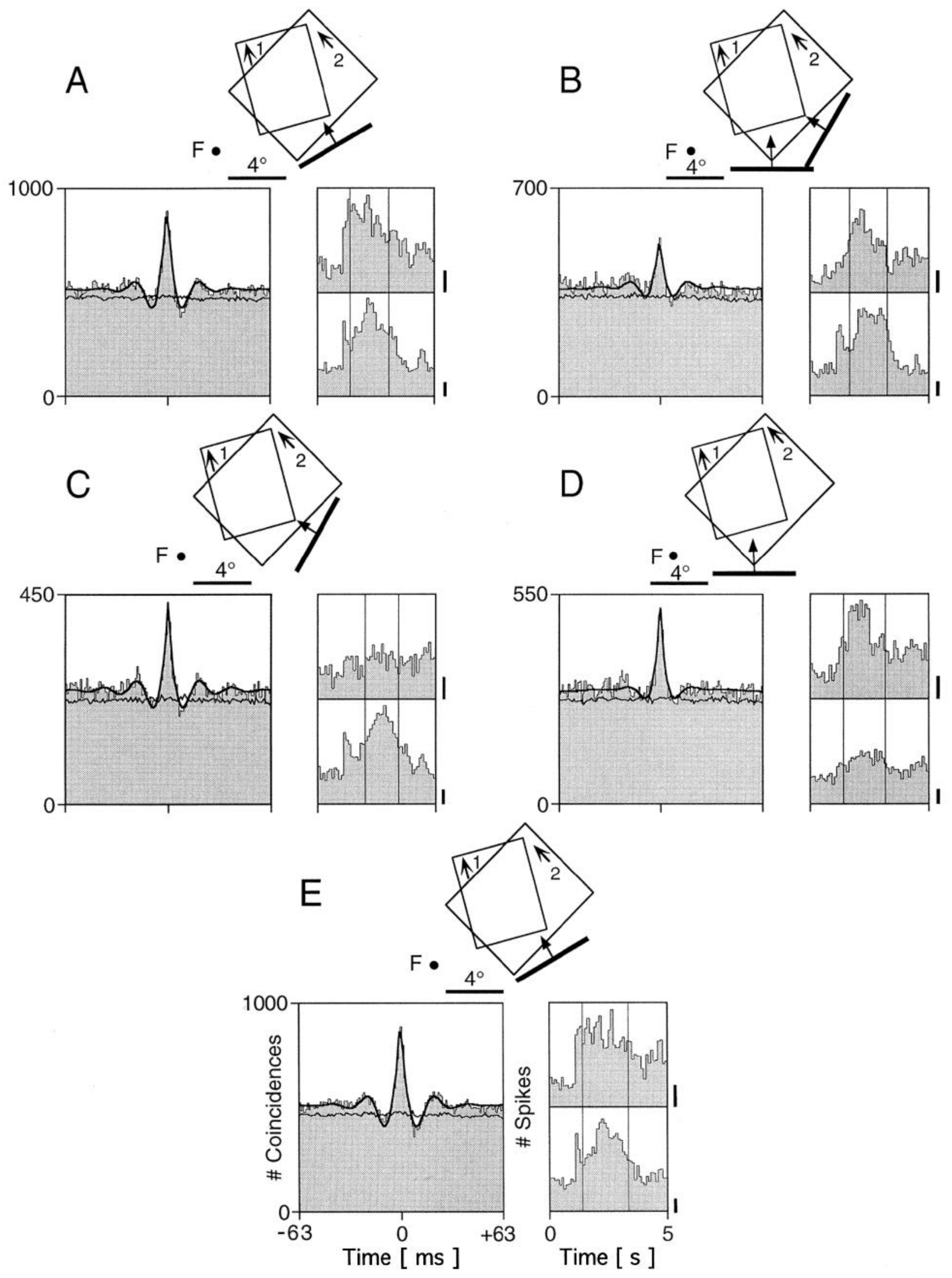

Figure 8. Dependence of synchronization on different directions of motion. Conventions are the same as in Figure 1 . The single-bar configuration $(A$, repetition in $E)$ results in a strong correlation $(\mathrm{NC}=65.0 \%$ in $A$ and $68.6 \%$ in $E)$, which is substantially reduced in the dual-bar configuration $(B$; $\mathrm{NC}=36.8 \%)$. Stimulation with only one of the bars used in the dual-bar configuration $(C$ and $D)$ results in both cases in a similarly pronounced correlation as in the single-bar configuration in $A(\mathrm{NC}=74.5 \%$ in $C$ and $69.3 \%$ in $D)$. The scale bars for the PSTHs correspond to 40 spikes/sec. 


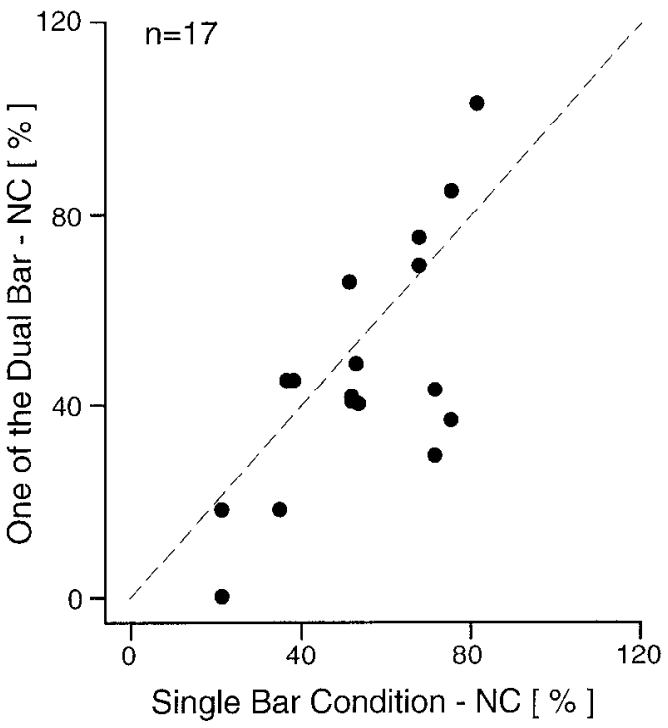

Figure 9. Scatter plot of NC values obtained for presentation of one of the bars of the dual-bar (ordinate) versus those obtained for the single-bar (abscissa) configuration ( $n=17)$. Most dots scatter around the dashed line indicating equal values for both conditions. Only in a few cases did the single-bar condition result in a considerably stronger correlation.

\section{Stimulus coordination and potential effects of eye movements}

The quantitative analysis and direct inspection of the shift predictors of all correlograms computed in this study have shown that all of them were flat, and therefore external sources of synchronization, which are linked to the stimulus, cannot have caused the peaks in the correlograms. However, small eye movements that are unavoidably present in awake animals could be considered as a common source of activation if they shift the stimuli over the RFs in a direction that results in activation of the cells at both recording sites. Because the eye movements are not temporally locked to the stimulus, a potential synchronizing effect would not show up in the shift predictor. To test whether such onset of motion events could have a synchronizing effect resulting in sharp peaks as they are observed in this study, we investigated the stimulus-induced correlation caused by a bar that started motion within the RFs in 14 pairs of multi-unit recording sites. Note that the instantaneous acceleration of this stimulus to its final speed corresponds to a much more rapid transient than that caused by a saccade, and thus should have a much more precise synchronizing effect. To estimate the stimulus-induced correlation, the shift predictor was computed, as described in Materials and Methods, within a window starting $300 \mathrm{msec}$ before motion onset and cxtending until $300 \mathrm{mscc}$ aftcr motion onset. Both quantitative analysis and visual inspection revealed only a broad hump in the predictor correlogram. This broad peak is the expected reflection of the sharp and simultaneous increase of the discharge rate at both recording sites. Its duration exceeds that of the correlogram because the analysis window includes only part of the response. There was never an indication of a sharp peak in the predictor correlogram even though 13 of the cases showed sharp peaks in cross-correlograms. This excludes that the distinct sharp peaks observed in this study were attributable to the more gradual changes of stimulus motion caused by small saccades.

\section{DISCUSSION}

The results of the present study demonstrate first that spatially segregated neurons in area MT of awake behaving primates can synchronize their responses to light stimuli with a precision in the millisecond range and, second, that this synchronization depends critically on the stimulus conditions. Whenever discharges were correlated, the correlation peaks were narrow and centered around zero delay, indicating that correlated discharges were coincident within intervals of a few milliseconds. Flat shift predictors indicate that these correlations cannot be accounted for by stimulus coordination. Similarly, the failure to find sharp stimulusinduced peaks in response to instantaneous onset of motion excludes the possibility that eye movements may have caused the correlations. This is not unexpected because cells in the extrastriate visual cortex do not lock with a precision of 2-4 msec to such sensory events as would be needed to generate the sharp peaks observed in this study. Furthermore, correlation peaks caused by stimulus coordination would reflect the differences in response latencies of the recorded neurons by a corresponding shift from the origin. Because response latencies of MT neurons, and hence their differences, cover a range of $>150 \mathrm{msec}$ (Raiguel et al,, 1989), the finding that all peaks were centered with only minimal deviations around zero is incompatible with the assumption that peaks were attributable to stimulus coordination.

Unexpectedly, in the recorded sample only a weak relation was found between correlation strength and the difference between the direction preferences of the respective neurons. Whether this reflects a common property of the coupling among neurons or whether it is attributable to the fact that data were recorded only from sites exhibiting strong correlations cannot be decided. It is conceivable that weak correlations are indeed more frequent among recording sites with large differences in preferred directions.

The present study concentrated on the stimulus dependence of synchronization and was not designed to estimate the frequency of correlation betwecn different cclls in MT. I Iowever, based on our previous experience with correlation studies in the visual cortex of anesthetized cats, it is our impression that there is no qualitative difference between the incidence of correlations in area MT and in the visual cortex of cats. The frequency of correlated pairs of neurons for cat area 17 has been estimated by several studies to be between 25 and $80 \%$, depending on the experimental approach (Toyama et al., 1981; Michalski et al., 1983; Ts'o et al., 1986; Hata et al., 1991). Similar proportions have also been found in V1 and inferotemporal cortcx (IT) of monkeys (Krüger and Aiple, 1988; Ts'o and Gilbert, 1988; Ahmed and Hammond, 1991; Gawne and Richmond, 1993). The main reason for excluding recording constellations from analysis was that the two sites did not fulfill the criteria described in Materials and Methods and not that they lacked correlation when activated with a single bar. In such situations, either the preferred directions of motion were too similar and the tuning too wide to allow for differential stimulation with the dual-bar configuration or preferred directions were too different to allow for common stimulation with a single bar. The number of sites that did not correlate even though they fulfilled our requirements was not much higher than the sites that did.

Synchronization was found to be strongest if responses were evoked with a single bar moving in a direction intermediate between the preferences of the neurons at both recording sites. It decreased markedly or disappeared altogether when responses were elicited with two bars, each of which activated only one of 
A
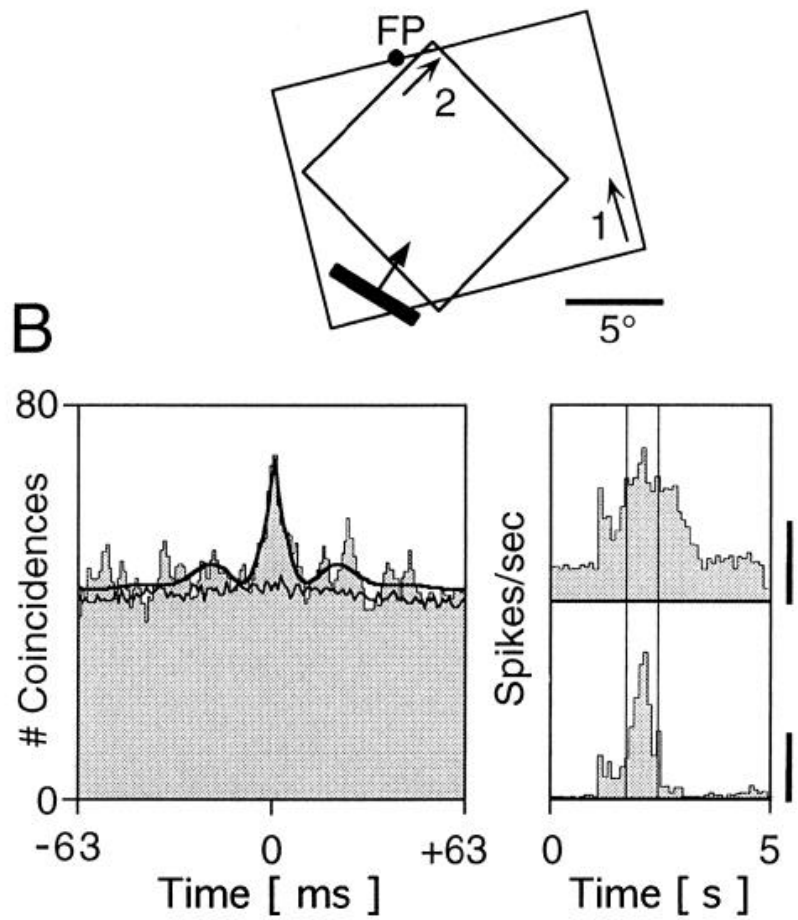
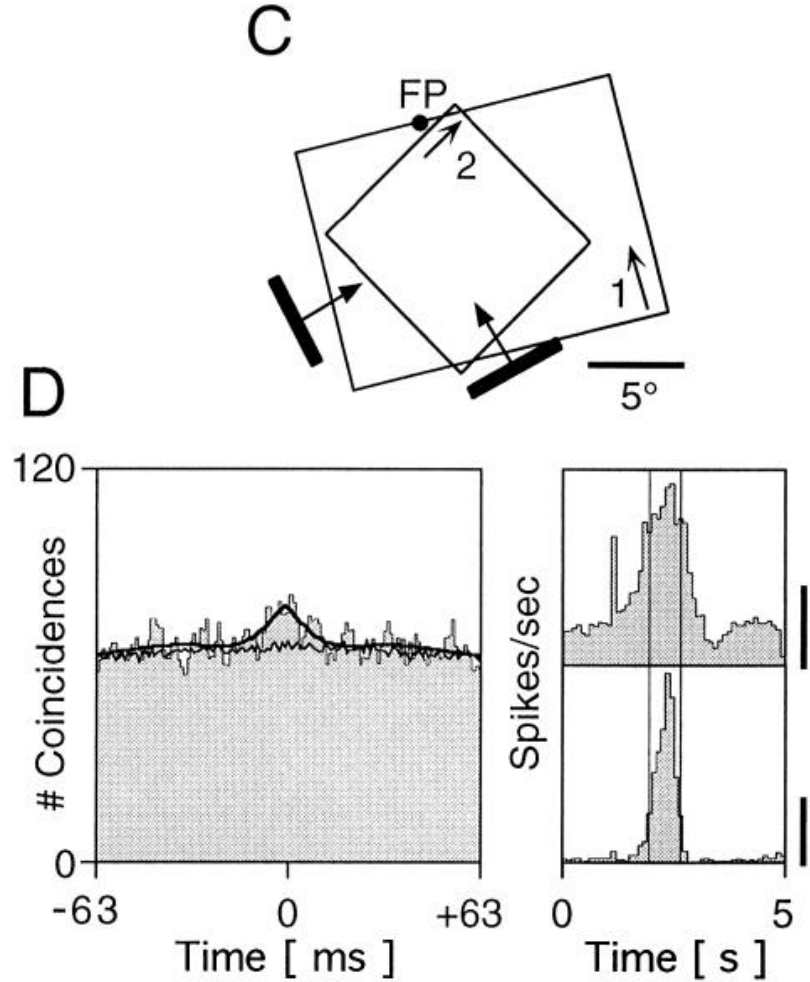

Figure 10. Dependence of synchronization between individual neurons on single- and dual-bar configurations. $A$, $C$, Plots of the RFs and stimulus configurations. $A$ depicts the single- and $C$ the dual-bar configuration. Three blocks of 20 trials were recorded in alternation for each stimulus condition. Cross-correlograms and PSTHs obtained for the single-bar condition are shown in $B$ and those for the dual-bar condition in $D$. Stimuli began to move $1 \mathrm{sec}$ after trial start and continued moving for $2 \mathrm{sec}$. The scale bars for the PSTHs correspond to $20 \mathrm{spikes} / \mathrm{sec}$. Other conventions as in Figure 1 . Note the pronounced synchronization in the single-bar condition and the weak residual synchronization in the dual-bar condition.

the two sites. This effect was robust because it occurred in all pairs, the average reduction factor being $\sim 6$. The possibility that the reduced correlation in the dual-bar condition could have been attributable to a different activation of another set of cells exhibiting weaker correlations can be ruled out because single-unit pairs showed the same effect.

This reduction of synchronization in the dual-bar condition can also not be attributed to the mere presence of two stimuli, because the crossing-bar configuration did not lead to a systematic reduction of synchrony. It can also be excluded that the specific direction of motion of the bar presented in the single- and the crossingbar condition is the principal cause for the presence of correlation. The results demonstrate that single bars with quite different orientations and directions of motion induce synchronized responses as long as they activate both sites sufficiently. Even the bars used in the dual-bar configuration which, when presented together, produced only little synchrony, evoked well synchronized responses when presented alone. In conclusion then, the critical variable determining synchronization is whether the responses at the two recording sites are evoked by a single stimulus or by two different stimuli distinguished by different directions of motion.

This conclusion is supported by the observation that the residual synchronization observed in part of the dual-bar conditions correlates well and in a predictable manner with the extent to which each of the bars coactivates the respective nondominant site when presented alone. Thus, the amount of synchrony reflects the relative contribution that a stimulus makes to the activation of distributed neurons. Synchrony is maximal if the majority of action potentials at both sites are evoked by the same stimulus, it is minimal if responses at the two sites are caused by different stimuli, and it is intermediate if there is cross-activation of the two sites by either one or both of the two stimuli.

This interpretation of the present data is supported by previous studies describing stimulus-dependent changes of correlation in the visual cortex and lateral geniculate nucleus of anesthetized cats and monkeys (Gray et al., 1989; Engel et al., 1991a,b; Kreiter et al., 1992; Neuenschwander and Singer, 1994; Sillito et al., 1994) and in the auditory system (Dickson and Gerstein, 1974; Eggermont et al., 1983; Frostig et al., 1983; Voigt and Young, 1985; Epping and Eggermont, 1987; Espinosa and Gerstein, 1988; Eggermont, 1991; Ahissar et al., 1992) of anesthetized cats and frogs. No dependence of synchronization on different stimulus constellations consisting of one or two fourier descriptor patterns out of a set of three has been found for closely spaced cells in the IT of awake, fixating macaque monkeys (Gochin et al., 1991). This result does not contradict the present results, because we found that changing the stimulus per se is not sufficient to change synchronization. Rather, it is necessary to change the source of activation from a common stimulus for both neurons to two different stimuli with each one activating selectively only one but not the other cell. Because the study has not investigated whether such a constellation of stimulus conditions ever happened, it is not clear whether similar results as in MT would also appear in IT.

An explanation for stimulus-dependent changes in synchronization strength could have resulted from differential activation of presynaptic neurons providing common input to the recorded neurons (Perkel et al., 1967b; Moore et al., 1970), the single-bar 
condition activating common input cells more effectively than the dual-bar constellation. Most of the excitatory synapses on cortical neurons come from neighboring cells. Thus, the quantitatively most important sources of common input in the single-bar conditions are nearby cells in MT preferring directions of motion intermediate between those preferred by the recorded cells. In addition, shared input is expected from cells in other cortical areas such as V1, V2, V3, and MST, provided that their RFs and direction preferences overlap with those of both recording sites. For the dual-bar condition, the amount of activity arriving via these shared inputs depends on the tuning width for orientation and direction of motion of the cells providing common input. If their tuning is similar to or broader than that of the recorded cells, they will also be activated well in the dual-bar condition. Thus, the mcan activation of the pool of MT and MST cells providing common input is likely to be similar in the single- and the dual-bar condition. However, more sharply tuned input cells as are found in V1, V2, and V3 (Orban, 1991) will provide less common input in the dual-bar condition because they will respond less vigorously. Thus, in view of the preponderance of shared input from neighboring neurons that are similarly activated in both stimulus conditions, a partial but not a complete reduction in the anount of common input is expected for the dual compared with the single-bar condition. This suggests that changes in the amount of common input could contribute to a mechanism causing the observed effect but are not sufficient to explain it completely. An alternative interpretation of the results is that response synchronization is not primarily attributable to common input in passive feedforward networks, but actually results from dynamic interactions among reciprocally coupled networks. Simulation studies have shown that networks showing basic features of cortical architecture can indeed reproduce similar stimulus-dependent changes of synchronization as those observed in the present experiments (König and Schillen, 1990; Wang et al., 1990; Grossberg and Somers, 1991; Horn and Usher, 1991; Horn et al., 1991; Sporns et al., 1991; Arndt et al., 1992; Hansel and Sompolinsky, 1992; Neven and Aertsen, 1992; Ritz et al., 1994a; Schillen and König, 1994; Sompolinsky and Tsodyks, 1994). The finding that firing patterns in MT deviate from the Poisson distribution typically assumed in passive feedforward models is consistent with the notion that the synchronization phenomena in MT are actually the result of highly dynamic interactive processes among reciprocally coupled neurons (Kreiter and Singer, 1992).

\section{Functional significance}

As outlined in the introduction, it is generally recognized that sufficiently precise and efficient stimulus descriptions can only be obtained by conjoint evaluation of the responses of different cells activated by the same stimulus, i.e., by exploiting a population code. Under natural viewing conditions, the evaluation of population codes is complicated by the presence of numerous contours, which evoke simultaneous responses in multiple populations of interconnected neurons. When stimulus configurations change, the constellations of neurons activated by different contours also change, but many neurons will remain equally active despite their altered relation to different populations. Thus, a mechanism is required that permits identification of responses evoked by an individual stimulus and to distinguish them from responses related to other, simultaneously present contours belonging to other objects or to the background. This is necessary to avoid false conjunctions during further processing. Such selection can be achieved by raising conjointly the saliency of responses originating from the same contour or object. However, increasing the saliency of responses by enhancing their rate may not suffice to disambiguate population codes because the selected responses to different contours would be similarly salient and again not distinguishable. In cortical networks in which neurons receive highly convergent input and in which activation depends on cooperation, a very efficient way to raise conjointly and selectively the saliency of a subpopulation of responses is to synchronize the respective spikes (Abeles, 1991; Bernander et al., 1994) (for review of theoretical implications and experimental data, see Singer and Gray, 1995). The synchronously arriving input signals summate particularly well in target cells and hence are more salient or effective than asynchronous inputs. The selectivity of this process results from the fact that only those inputs that are synchronous profit from this saliency-enhancing effect. The shorter the integration interval over which postsynaptic neurons can effectively summate inputs, the more precise this selection will be. If this interval is in the range of milliseconds, numerous populations could be defined nearly simultaneously by multiplexing.

Certain features of cortical neurons and their connections favor a mechanism of response selection by synchrony. First, the high degree of convergence at cortical pyramidal neurons, the usually low efficacy of individual excitatory inputs, and the short temporal interval over which cortical cells effectively summate (Braitenberg and Schüz, 1991; Mason et al., 1991; Kim and Connors, 1993; Thomson and West, 1993; Thomson et al., 1993; Deuchars et al., 1994) make synchronous inputs particularly effective in driving cortical neurons. Second, synapses among excitatory cortical neurons tend to exhibit marked frequency attenuation (Thomson and West, 1993), whereas excitatory input to inhibitory neurons shows very effective temporal summation (Thomson et al., 1993). Both mechanisms together constrain the possibility to ensure propagation of responses by increasing discharge rates. The propagation of synchronized activity, in contrast, is not attenuated by these mechanisms because synchronized inputs reach threshold even if they discharge at low frequencies, and inhibition elicited by coactivation of interneurons will come too late to prevent responses in pyramidal cells because synchronous EPSPs reach firing level virtually instantaneously. Exploiting response synchronization for the selection of response constellation also has certain advantages with respect to the organization of cortical operations. First, synchrony can be established rapidly and in fast succession for different constellations without requiring changes in circuitry (Aertsen et al., 1989, 1994; Boven and Aertsen, 1990; Aertsen and Prei $\beta 1,1991$; Somers and Kopell, 1993; Grannan et al., 1994). This separation of processing in time allows for virtually simultaneous, but largely independent, processing of different population-coded stimuli within the same network of interconnected neurons (König and Schillen, 1990; Wang et al., 1990; Grossberg and Somers, 1991; Horn and Usher, 1991; Sporns et al., 1991; Arndt et al., 1992; Hansel and Sompolinsky, 1992; Neven and Aertsen, 1992; Grannan et al., 1994; Ritz et al., 1994a,b; Schillen and König, 1994; Sompolinsky and Tsodyks, 1994). Second, activity of neurons that are not recruited into any synchronized assembly will remain rather inefficient because their EPSPs cannot benefit from spatial summation. This improves the signal-to-noise ratio for the organized activity patterns of populations. Third, no additional binding neurons are required, as e.g., a separate set of higherorder cells, which represent the different relations of the lowerorder neurons activated by different stimuli. Fourth, firing rate can be preserved as an independent coding dimension for stimulus features such as orientation or direction of motion because it 
is not needed to express relational information as would be the case if assemblies were distinguished by joint enhancement of discharge rates.

Taken together, these considerations suggest that synchronization of spikes within a precision range of milliseconds could serve as an efficient mechanism to define and select population responses for further joint processing. The present data show that synchronization in MT occurs with the required precision; is attributable to active neuronal processes and not merely locked to the spatiotemporal structure of stimuli; and exhibits the postulated dependency on stimulus configuration. Thus, it has all the properties that would be required if it were to be exploited to distinguish population-coded representations of different stimuli: to associate a set of neurons responding to the same stimulus and to segrcgatc this set from cells coding for different stimuli.

\section{REFERENCES}

Abeles M (1982) Local cortical circuits. Berlin, Heidelberg, New York: Springer.

Abeles M (1991) Corticonics. Cambridge, UK: Cambridge UP.

Aertsen A, Prei $\beta 1$ H (1991) Dynamics of activity and connectivity in physiological neuronal networks. In: Nonlinear dynamics and neural networks (Schuster H, ed), pp 281-301. Weinheim: VCII.

Aertsen A, Gerstein G, Johannesma P (1986) From neuron to assembly: neuronal organization and stimulus representation. In: Brain theory (Palm G, Aertsen A, eds), pp 7-24. Berlin: Springer.

Aertsen A, Erb M, Palm G (1994) Dynamics of functional coupling in the cerebral cortex: an attempt at a model-based interpretation. Physica D 75:103-128.

Aertsen AMHJ, Gerstein GL (1985) Evaluation of neuronal connectivity: sensitivity of cross-correlation. Brain Res 340:341-354.

Aertsen AMHJ, Gerstein GL, Habib MK, Palm G (1989) Dynamics of neuronal firing correlation: modulation of "effective connectivity." J Neurophysiol 61:900-917.

Ahissar M, Ahissar E, Bergman H, Vaadia E (1992) Encoding of soundsource location and movement: activity of single neurons and interactions between adjacent neurons in the monkey auditory cortex. $J$ Neurophysiol 67:203-215.

Ahmed B, Hammond P (1991) Orientation bias of cat dorsal lateral geniculate cells: directional analysis of the major axis of the receptive field centre. Exp Brain Res 84:676-679.

Arndt M, Dicke P, Erb M, Eckhorn R, Reitboeck HJ (1992) Two-layered physiology-oriented neuronal network models that combine dynamic feature linking via synchronization with a classical associative memory. In: Neural network dynamics (Taylor JG, Caianello ER, Cotterill RMJ, Clark JW, eds), pp 140-154. New York: Springer.

Bernander Ö, Koch C, Usher M (1994) The effect of synchronized inputs at the single neuron level. Neural Comp 6:622-641.

Born RT, Tootell RBH (1992) Segregation of global and local motion processing in primate middie temporal visual area. Nature 357:497-499.

Buven K-H, Aertsen A (1990) Dynamics of activity in neuronal networks give rise to fast modulations of functional connectivity. In: Parallel processing in neural systems and computers (Eckmiller R, Hartmann G, Hauske $(\dot{i}$, eds), pp 53-56. North-Holland: Elsevier.

Boynton RM, Baron WS (1975) Sinusoidal flicker characteristics of primate cones in response to heterochromatic stimuli. J Opt Soc Am 65:1091-1100.

Braitenberg V (1978) Cell assemblies in the cerebral cortex. In: Lecture notes in biomathematics 21, theoretical approaches in complex systems (Heim R, Palm G, eds), pp 171-188. Berlin: Springer.

Braitenberg V, Schüz A (1991) Anatomy of the cortex-statistics and geometry. Berlin: Springer.

Brillinger DR, Bryant Jr HL, Segundo JP (1976) Identification of synaptic interactions. Biol Cybern 22:213-228.

Britlen KH, Shadlen MN, Newsone WT, Movshon JA (1992) The andysis of visual motion: a comparison of neuronal and psychophysical performance. J Neurosci 12:4745-4765.

Bryant Jr HL, Ruiz Marcos A, Segundo JP (1973) Correlations of neuronal spike discharges produced by monosynaptic connections and by common inputs. J Neurophysiol 36:205-225.

Churchland PS, Sejnowski TJ (1992) The computational brain. Cambridge, MA: MIT.
Cowey A, Marcar VL (1992) The effect of removing superior temporal cortical motion areas in the macaque monkey: I. Motion discrimination using simple dots. Eur J Neurosci 4:1219-1227.

Desimone R, Ungerleider LG (1986) Multiple visual areas in the caudal superior temporal sulcus of the macaque. J Comp Neurol 248:164-189.

Desimone R, Schein SJ, Moran J, Ungerleider LG (1985) Contour, color and shape analysis beyond the striate cortex. Vision Res 25:441-452.

Deuchars J, West DC, Thomson AM (1994) Relationships between morphology and physiology of pyramid-pyramid single axon connections in rat neocortex in vitro. J Physiol (Lond) 478:423-435.

Dickson JW, Gerstein GL (1974) Interactions between neurons in auditory cortex of the cat. J Neurophysiol 37:1239-1261.

Dubner R, Zeki SM (1971) Response properties and receptive fields of cells in an anatomically defined region of the superior temporal sulcus in the monkey. Brain Res 35:528-532.

Edelman GM, Mountcastle VB (1978) The mindful brain. Cambridge, MA: MIT.

Eggermont JJ (1990) The correlative brain-theory and experiment in neural interaction. Berlin: Springer.

Eggermont JJ (1991) Neuronal pair and triplet interactions in the auditory midbrain of the leopard frog. J Neurophysiol 66:1549-1563.

Eggermont JJ, Epping WJM, Aertsen AMHJ (1983) Stimulus dependent ncural corrclations in the auditory midbrain of the grassfrog (Rana temporaria L.). Biol Cybern 47:103-117.

Engel AK, König P, Singer W (1991a) Direct physiological evidence for scene segmentation by temporal coding. Proc Natl Acad Sci USA 88:9136-9140.

Engel AK, Kreiter AK, König P, Singer W (1991b) Synchronization of oscillatory neuronal responses between striate and extrastriate visual cortical areas of the cat. Proc Natl Acad Sci USA 88:6048-6052.

Epping WJM, Eggermont JJ (1987) Coherent neural activity in the auditory midbrain of the grassfrog. J Neurophysiol 57:1464-1483.

Espinosa IE, Gerstein GL (1988) Cortical auditory neuron interactions during presentation of 3-tone sequences: effective connectivity. Brain Res 450:39-50.

Frostig RD, Gottlieb Y, Vaadia E, Abeles M (1983) The effects of stimuli on the activity and functional connectivity of local neuronal groups in the cat auditory cortex. Brain Res 272:211-221.

Gattass R, Gross CG (1981) Visual topography of striate projection zone (MT) in posterior superior temporal sulcus of the macaque. J Neurophysiol 46:621-638.

Gawne TJ, Richmond BJ (1993) How independent are the messages carried by adjacent inferior temporal cortical neurons? J Neurosci 13:2758-2771.

Gerstein GL, Aertsen AMHJ (1985) Representation of cooperative firing activity among simultaneously recorded neurons. J Neurophysiol 54:1513-1528.

Gerstein GL, Perkel DH (1972) Mutual temporal relationships among neuronal spike trains. Biophys J 12:453-473.

Gerstein GL, Aertsen A, Bloom M, Espinosa E, Evanczuk S (1985) Multi-neuron experiments: observation of state in neural nets. In: Complex systems--operational approaches (Haken H, ed), New York: Springer.

Gerstein GL, Bedenbaugh P, Aertsen AMHJ (1989) Neuronal assemblies. IEEE Trans Biomed Eng 36:4-14.

Gochin PM, Miller EK, Gross CG, Gerstein GL (1991) Functional interactions among neurons in inferior temporal cortex of the awake macaque. Exp Brain Res 84:505-516.

Gochin PM, Colombo M, Dorfman GA, Gerstein GL, Gross CG (1994) Neural ensemble coding in inferior temporal cortex. J Neurophysiol 71:2325-2337.

Grannan ER, Kleinfeld D, Sompolinsky H (1994) Stimulus-dependent synchronization of neuronal assemblies. Neural Comp 5:550-569.

Gray CM, König P, Engel AK, Singer W (1989) Oscillatory responses in cat visual cortex exhibit inter-columnar synchronization which reflects global stimulus patterns. Nature 338:334-337.

Grossberg S (1980) How does a brain build a cognitive code? Psychol Rev 87:1-51.

Grossberg S, Somers D (1991) Synchronized oscillations during cooperative feature linking in a cortical model of visual perception. Neural Networks 4:453-466.

Hansel D, Sompolinsky H (1992) Synchronization and computation in a chaotic neural network. Phys Rev Lett 68:718-721. 
Hata Y, Tsumoto T, Sato H, Tamura H (1991) Horizontal interactions between visual cortical neurons studied by cross-correlation analysis in the cat. J Physiol (Lond) 441:593-614.

Hebb DO (1949) The organization of behavior. New York: Wiley.

Henry GH (1985) Physiology of cat striate cortex. In: Cerebral cortex (Peters A, Jones EG, eds), pp 119-155. New York: Plenum.

Hopfield JJ (1982) Neural networks and physical systems with emergent collective computational abilities. Proc Natl Acad Sci USA 79:2554-2558.

Hopfield JJ, 'Iank DW (1991) Computing with neural circuits: a model. Science 233:625-633.

Horn D, Usher M (1991) Parallel activation of memories in an oscillatory neural network. Neural Comp 3:31-43.

Horn D, Sagi D, Usher M (1991) Segmentation, binding, and illusory conjunctions. Neural Comp 3:510-525.

Hubel DH, Wiesel TN (1959) Receptive fields of single neurons in the cat striate cortex. J Physiol (Lond) 148:574-591.

Hubcl DH, Wiesel TN (1962) Receptive fields, binocular interaction and functional architecture in the cat's visual cortex. J Physiol (Lond) 160:106-154.

Kim HG, Connors BW (1993) Apical dendrites of the neocortex: correlation between sodium- and calcium-dependent spiking and pyramidal cell morphology. J Neurosci 13:5301-5311.

Kirkwood PA (1979) On the use and interpretation of cross correlation measurements in the mammalian central nervous system. J Neurosci Methods 1:107-132.

König P (1994) A method for the quantification of synchrony and oscillatory properties of neural activity. J Neurosci Methods 54:31-37.

König P, Schillen TB (1990) Segregation of oscillatory responses by conflicting stimuli-desynchronizing connections in neural oscillator layers. In: Parallel processing in neural systems and computers (Eckmiller $\mathbf{R}$, Hartmann G, Hauske G, eds), pp 117-120. North Holland: Elsevier.

Kreiter AK, Singer W (1992) Oscillatory neuronal responses in the visual cortex of the awake macaque monkey. Eur J Neurosci 4:369-375.

Kreiter AK, Singer W (1993) Synchronization of neural activity depends on global stimulus properties in the awake macaque monkey. In: Gene-brain-behaviour (Elsner N, Heisenberg M, eds), Stuttgart, New York: Thieme.

Kreiter AK, Singer W (1994) Global stimulus arrangement determines synchronization of neuronal activity in the awake macaque monkey. Fur J Neurosci (Suppl) 7:153.

Kreiter AK, Engel AK, Singer W (1992) Stimulus dependent synchronization in the caudal supcrior temporal sulcus of macaque monkeys. Soc Neurosci Abstr 18:12.

Krüger J, Aiple F (1988) Multimicroelectrode investigation of monkey striate cortex: spike train correlations in the infragranular layers. J Neurophysiol 60:798-828.

Lagae L, Gulyás B, Raiguel S, Orban GA (1989) Laminar analysis of motion information processing in macaque V5. Brain Res 496:361-367.

Lagae L, Raiguel S, Orban GA (1993) Speed and direction selectivity of macaque middle temporal neurons. J Neurophysiol 69:19-39.

Livingstone MS, Hubel DH (1988) Segregation of form, color, movement, and depth: anatomy, physiology, and perception. Science 240:740-749.

Marcar VL, Cowey A (1992) The effect of removing superior temporal cortical motion areas in the macaque monkey. II. Motion discrimination using random dot displays. Eur J Neurusci 4:1228-1238.

Mason A, Nicoli A, Stratford K (1991) Synaptic transmission between individual pyramidal neurons of the rat visual cortex in vitro. J Neurosci 11:72-84.

Maunsell JHR, Newsome WT (1987) Visual processing in monkey extrastriate cortex. Annu Rev Neurosci 10:363-401.

Maunsell JHR, Van Essen DC (1983a) Functional properties of neurons in middle temporal visual area of the macaque monkey. I. Selectivity for stimulus direction, speed, and orientation. J Neurophysiol 49:1127-1147

Maunsell JHR, Van Essen DC (1983b) Functional properties of neurons in middle temporal visual area of the macaque monkey. II. Binocular interactions and sensitivity to binocular disparity. $J$ Neurophysiol 49:1148-1167.

Michalski A, Gerstein GL, Czarkowska J, Tarnecki R (1983) Interactions between cat striate cortex neurons. Exp Brain Res 51:97-107.

Mikami A (1992) Spatiotemporal characteristics of direction-selective neurons in the middle temporal visual area of the macaque monkeys. Exp Brain Res 90:40-46.
Mikami A, Newsome WT, Wurtz RH (1986a) Motion selectivity in macaque visual cortex. I. Mechanisms of direction and speed selectivity in extrastriate area MT. J Neurophysiol 55:1308-1327.

Mikami A, Newsome WT, Wurtz RH (1986b) Motion selectivity in macaque visual cortex. II. Spatiotemporal range of directional interactions in MT and V1. J Neurophysiol 55:1328-1339.

Milner PM (1974) A model for visual shape recognition. Psychol Rev $81: 521-535$

Moore GP, Segundo JP, Perkel DH, Levitan H (1970) Statistical signs of synaptic interaction in neurons. Biophys $\mathrm{J}$ 10:876-900.

Movshon JA, Adelson EH, Gizzi MS, Newsome WT (1985) The analysis of moving visual patterns. In: Pattern recognition mechanisms (Chagas C, Gattass R, Gross CG, eds), pp 117-151. Berlin: Springer.

Murasugi CM, Salzman CD, Newsome WT (1993) Microstimulation in visual area MT: effects of varying pulse amplitude and frequency. J Neurosci 13:1719-1729.

Neuenschwander S, Singer W (1994) Synchronized oscillations across laminae in the cat lateral geniculate nucleus are stimulus dependent. Soc Neurosci Abstr 20:133.

Neven H, Aertsen A (1992) Rate coherence and event coherence in the visual cortex: a neuronal model of object recognition. Biol Cybern 67:309-322.

Newsome WT, Paré EB (1988) A selective impairment of motion perception following lesions of the middle temporal visual area (MT). J Neurosci 8:2201-2211.

Newsome WT, Wurtz RH, Dürsteler MR, Mikami A (1985) Deficits in visual motion processing following ibotenic acid lesions of the middle temporal visual area of the macaque monkey. J Neurosci 5:825-840.

Newsome WT, Mikami A, Wurtz RH (1986) Motion selectivity in macaque visual cortex. III. Psychophysics and physiology of apparent motion. J Neurophysiol 55:1340-1351.

Newsome WT, Britten KH, Movshon JA (1989) Neuronal correlates of a perceptual decision. Nature 341:52-54.

Olavarria JF, DeYoe EA, Knierim JJ, Fox JM, Van Essen DC (1992) Neural responses to visual texture patterns in middle temporal area of the macaque monkey. J Neurophysiol 68:164-181.

Orban GA (1984) Neuronal operations in the visual cortex. Berlin: Springer.

Orban GA (1991) Quantitative electrophysiology of visual cortical neurones. In: Vision and visual dysfunction, Vol 4, The neural basis of visual function (Leventhal AG, ed), pp 173-222. London: Macmillan.

Palm G (1982) Neural assemblies. Heidelberg: Springer.

Palm G (1990) Cell assemblies as a guideline for brain research. Concepts Neurosci 1:133-147.

Palm G, Aertsen AMHJ, Gerstein GL (1988) On the significance of correlations among neuronal spike trains. Biol Cybern 59:1-11.

Perkel DH (1975) Presynaptic inhibition: detection through statistical analysis of impulse trains. Brain Res 96:330-336.

Perkel DH, Gerstein GL, Moore GP (1967a) Neuronal spike trains and stochastic point processes. I. The single spike train. Biophys J 7:391-418.

Perkel DH, Gerstein GL, Moore GP (1967b) Neuronal spike trains and stochastic point processes. II. Simultaneous spike trains. Biophys J 7:419-440.

Press WH, Flannery BP, Teukolsky SA, Vetterling WT (1986) Numerical recipes. Cambridge, UK: Cambridge UP.

Raiguel SE, Layae L, Gulyás B, Orban GA (1989) Response latencies of visual cells in macaque areas V1, V2 and V5. Brain Res 493:155-159.

Ritz R, Gerstner W, Fuentes U, van Hemmen JL (1994a) A biologically motivated and analytically soluble model of collective oscillations in the cortex. II. Application to binding and pattern segmentation. Biol Cybern 71:349-359.

Ritz R, Gerstner W, van Hemmen JL (1994b) Associative binding and segregation in a network of spiking neurons. In: Models of neural networks, Vol 2 (Domany E, van Hemmen JL, Schulten K, eds), pp 175-219. New York: Springer.

Rodman HR, Albright TD (1989) Single-unit analysis of pattern-motion sclcetive propertics in the middle temporal visual arca (MT). Exp Brain Res 75:53-64.

Rolls ET (1992) Neurophysiological mechanisms underlying face processing within and beyond the temporal cortical visual areas. Philos Trans R Soc Lond Biol 335:11-21.

Rumelhart DE, McClelland JL (1986) Parallel distributed processing: explorations in the microstructure of cognition, Vol 1, Foundations. Cambridge, MA: MIT. 
Salzman CD, Britten KH, Newsome WT (1990) Cortical microstimulation influences perceptual judgements of motion direction. Nature 346:174-177.

Salzman CD, Murasugi CM, Britten KH, Newsome WT (1992) Microstimulation in visual area MT: effects on direction discrimination performance. J Neurosci 12:2331-2355.

Schillen TB, König P (1994) Binding by temporal structure in multiple feature domains of an oscillatory neuronal network. Biol Cybern 70:397-405.

Schmidt EM (1984a) Instruments for sorting neuroelectric data: a review. J Ncurosci Methods 12:1-24.

Schmidt EM (1984b) Computer separation of multi-unit neuroelectric data: a review. J Neurosci Methods 12:95-111.

Sillito AM, Jones HE, Gerstein GL, West DC (1994) Feature-linked synchronization of thalamic relay cell firing induced by feedback from the visual cortex. Nature 369:479-482.

Singer W (1987) Activity-dependent self-organization of synaptic connections as a substrate of learning. In: The neural and molecular bases of learning (Changeux J-P, Konishi M, eds), pp 301-336. Chichester, UK: Wiley.

Singer W (1990) Search for coherence: a basic principle of cortical selforganization. Concepts Neurosci 1:1-26.

Singer W (1993) Synchronization of cortical activity and its putative role in information processing and learning. Annu Rev Physiol 55:349-374.

Singer W, Gray CM (1995) Visual feature integration and the temporal correlation hypothesis. Annu Rev Neurosci 18:555-586.

Snowden RJ, Treue S, Erickson RG, Andersen RA (1991) The responsc of MT and V1 neurons to transparent motion. J Neurosci 11:2768-2785.

Somers D, Kopell N (1993) Rapid synchronization through fast threshold modulation. Biol Cybern 68:393-407.

Sompolinsky H, Tsodyks M (1994) Segmentation by a network of oscillators with stored memories. Neural Comp 6:642-657.

Sporns O, Tononi G, Edelman GM (1991) Modeling perceptual grouping and figure-ground segregation by means of active reentrant connections. Proc Natl Acad Sci USA 88:129-133.

Stoner GR, Albright TD (1992) Neural correlates of perccptual motion coherence. Nature 358:412-414.

Thomson AM, West DC (1993) Fluctuations in pyramid-pyramid excitatory postsynaptic potentials modified by presynaptic firing pattern and postsynaptic membrane potential using paired intracellular recordings in rat neocortex. Neuroscience 54:329-346.

Thomson AM, Deuchars J, West DC (1993) Single axon excitatory postsynaptic potentials in neocortical interneurons exhibit pronounced paired pulse facilitation. Neuroscience 54:347-360.
Toyama K, Kimura M, Tanaka K (1981) Cross-correlation analysis of interneuronal connectivity in cat visual cortex. J Neurophysiol 46:191-201.

Ts'o DY, Gilbert CD (1988) The organization of chromatic and spatial interactions in the primate striate cortex. J Neurosci 8:1712-1727.

Ts'o DY, Gilbert CD, Wiesel TN (1986) Relationships between horizontal interactions and functional architecture in cat striate cortex as revealed by cross-correlation analysis. $J$ Neurosci 6:1160-1170.

Van Essen DC, Maunsell JHR, Bixby JL (1981) The middle temporal visual area in the macaque: myeloarchitecture, connections, functional properties and topographic organization. J Comp Neurol 199:293-326.

Voigt HF, Young ED (1985) Stimulus dependent neural correlation: an example from the cochlear nucleus. Exp Brain Rcs 60:594-598.

von dor Malsburg C (1985) Nervous structures with dynamical links. Ber Bunsen-Ges Phys Chem 89:703-710.

von der Malsburg C (1986) Am I thinking assemblies? In: Brain theory (Palm G, Aertsen A, eds), pp 161-176. Berlin: Springer.

von der Malsburg C, Schneider W (1986) A neural cocktail-party processor. Biol Cybern 54:29-40.

von der Malsburg C, Singer W (1988) Principles of cortical network organization. In: Neurobiology of neocortex (Rakic P, Singer W, eds), pp 69-99. Chichester, UK: Wiley.

Wang D, Buhmann J, von der Malsburg C (1990) Pattern segmentation in associative memory. Neural Comp 2:94-106.

Wurtz RH (1969) Visual receptive fields of striate cortex neurons in awake monkeys. J Neurophysiol 32:727-742.

Young MP, Yamane S (1992) Sparse population coding of faces in the inferotemporal cortex. Science 256:1327-1331.

Zeki SM (1974a) Functional organization of a visual area in the posterior bank of the superior temporal sulcus of the rhesus monkey. J Physiol (Lond) 236:549-573.

Zeki SM (1974b) Cells responding to changing image size and disparity in the cortex of the rhesus monkey. J Physiol (Lond) 242:827-841.

Zeki SM (1975) The functional organization of projections from striate to prestriate visual cortex in the rhesus monkey. Cold Spring Harb Symp Quant Biol 40:591-600.

Zipser D, Andersen RA (1988) A back-propagation programmed network that simulates response properties of a subset of posterior parietal neurons. Nature 331:679-684.

Zohary E, Shadlen M, Newsome WT (1994) Correlated neuronal discharge rate and its implications for psychophysical performance. Nature $370: 140-143$. 